University of Nebraska - Lincoln

DigitalCommons@University of Nebraska - Lincoln

Andrzej Rajca Publications

Published Research - Department of Chemistry

November 2007

\title{
Synthesis and Characterization of Novel Chiral Conjugated \\ Materials
}

Andrzej Rajca

University of Nebraska - Lincoln, arajca1@unl.edu

Makoto Miyasaka

University of Nebraska - Lincoln

Follow this and additional works at: https://digitalcommons.unl.edu/chemistryrajca

Part of the Chemistry Commons

Rajca, Andrzej and Miyasaka, Makoto, "Synthesis and Characterization of Novel Chiral Conjugated Materials" (2007). Andrzej Rajca Publications. 3.

https://digitalcommons.unl.edu/chemistryrajca/3

This Article is brought to you for free and open access by the Published Research - Department of Chemistry at DigitalCommons@University of Nebraska - Lincoln. It has been accepted for inclusion in Andrzej Rajca Publications by an authorized administrator of DigitalCommons@University of Nebraska - Lincoln. 


\title{
Synthesis and Characterization of Novel Chiral Conjugated Materials
}

\author{
Andrzej Rajca and Makoto Miyasaka
}

\section{1}

\section{Introduction}

Chirality is increasingly important in the design of organic $\pi$-conjugated materials. One of the aspects of the design involves optimization of achiral properties through the introduction of chirality. In this context, the inherent three-dimensional character of chirality and the control of intermolecular interactions associated with diastereomeric recognition provide a versatile handle for the optimization of supramolecular structures, film morphology and liquid crystalline order of $\pi$-conjugated polymers and oligomers in three dimensions [1-5]. These inherently achiral properties have an impact on optoelectronic coupling, which may affect the fabrication of light-emitting diodes, field effect transistors, photodiodes, photovoltaic cells, fluorescent sensors and other devices $[2,3,5]$. Another aspect of the design involves optimization of chiral counterparts of properties in optics (circular polarization of light), electronics (chiral transport of charge carriers), etc. [6-11]. The challenge in this area is to obtain materials with inherently strong chiral properties at the macromolecular level, rather than derived from an aggregate or a supramolecular structure. Such inherently strong chiral properties, approaching or exceeding in magnitude their achiral counterparts, would facilitate exploration of chiral properties of single molecule devices and the design of novel chiral materials.

For typical $\pi$-conjugated polymers, helical conformation in the $\pi$-conjugated back-

Published in Functional Organic Materials. Syntheses, Strategies, and Applications, edited by Thomas J.J. Müller and Uwe H.F. Bunz (Weinheim, Germany: WILEY-VCH Verlag GmbH \& Co. KGaA, 2007), as Chapter 15, pages 547-581. ISBN: 978-3-527-31302-0

Copyright $\odot 2007$ WILEY-VCH Verlag GmbH \& Co. KGaA.

Used by permission.

Andrzej Rajca and Makoto Miyasaka

Department of Chemistry

University of Nebraska-Lincoln

Hamilton Hall

Lincoln, NE 68588-0304

arajca1@unl.edu bone may be induced via the chiral nonracemic pendants, complexation of a chiral nonracemic compound or polymerization in chiral nematic liquid crystal (LC) [1214]. There are few structural motifs for nonracemic polymers with configurationally stable helical (and formally cross-conjugated) backbones such as polyisocyanides or with in-chain $\pi$-conjugated chirality $[12,15]$. However, the majority, if not all, of $\pi$ conjugated polymers only display significant nonracemic helicity in an aggregated or ordered form [12].

The introduction of angular connectors (e.g. 1,3-phenylenes, 2,7-naphthylenes) in the $\pi$-conjugated backbones may provide an oligomer with a preferred helical conformation. The nonracemic helicity of such foldamers, which may be induced via chiral nonracemic pendants or in-chain chirality (e.g. 1,1'-binaphthyls, [4] helicenes), is also associated with an aggregated form and it is solvent dependent [16, 17].

Another class of polymers and oligomers possess highly annelated (e.g. laddertype) chiral $\pi$-conjugated systems [18-21]. The oligomers with helical, ladder-type 
$\pi$-conjugated systems were found to be among molecules with the strongest chiral properties. Whereas helical polymers with ladder-type connectivity have been prepared with varied degrees of success $[18,19]$, a highly extended helical ladder-type $\pi$-conjugated system has not been attained.

This chapter addresses synthetic aspects of molecules with highly annelated chiral $\pi$-conjugated systems, with the focus on helicene-type oligomers [20]. In addition to synthesis, configurational stability (barriers for racemization) and selected chiroptical properties of such molecules will be discussed.

\section{2}

\section{Synthetic Approaches to Highly Annelated Chiral m-Conjugated \\ Systems}

\subsection{1}

\section{Helicenes}

$[n]$ Helicenes possess $n$ angularly annelated aromatic rings, forming a helically shaped $\pi$-conjugated system, such as six ortho-annelated benzene rings in [6]helicene (1) (Figure 15.1) [21]. For [n] helicenes with $n \geq 5$, the distortion from planarity due to steric repulsion of terminal rings is sufficient to allow for resolution of enantiomers. Because both high degree of annelation and significant strain have to be introduced into such it-systems, efficient syntheses of $[n]$ helicenes are challenging.

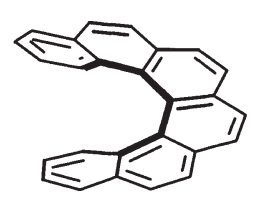

[6]helicene 1

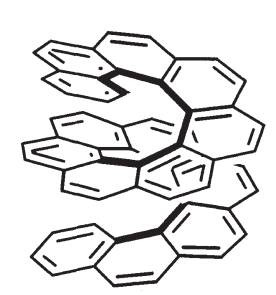

[14]helicene 4

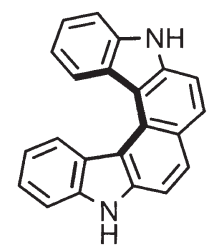

[6]pyrrolohelicene 2

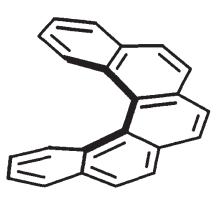

[5]helicene 3

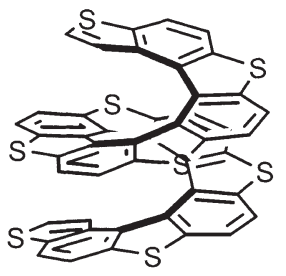

[15]thiahelicene 5

The first $[n]$ helicenes, [6]pyrrolohelicene (2) and [5]helicene (3), were reported in 1927 and 1933, respectively [22-24]. The synthesis of a non-racemic [ $n]$ helicene, [6]helicene (1), was first described by Newman and Lednicer in 1956 [25]. Photochemical syntheses developed during the 1960s and 1970s provided the longest [ $n$ ]helicenes to date, that is, $[n]$ helicenes [with up to $n=14$ benzene rings (4)] and [n]thiahelicenes [with up to $n=15$ alternating benzene and thiophene rings (5)] [26-30].

Recent work by Katz and coworkers led to the development of very efficient nonphotochemical, gram-scale syntheses of functionalized enantiopure $[n]$ helicenes $(n=$ 5,6 , and 7). These approaches were based on racemic syntheses and classical resolutions with a chiral auxiliary $[31,32]$.

The extraordinarily strong chiral properties of $[n]$ helicenes provide an impetus for the development of synthetic approaches to nonracemic $[n]$ helicenes for applications as organic materials. From this point of view, asymmetric syntheses of functionalized long $[n]$ helicenes $(n>7)$, and also $[n]$ helicene-like molecules and polymers with novel electronic structures and material properties, are important. The properties of helicenes related to materials are relatively unexplored, compared with the more synthetically accessible $\pi$-conjugated molecules and polymers. Notably, redox states of helicenes are practically unknown $[33,34]$. Assembly of helicenes on surfaces, their uses as liquid crystals, chiral sensors, ligands or additives for asymmetric synthesis and helicene-biomolecule interactions are in the exploratory stages [35-43].

In general, the synthesis of $[n]$ helicenes involves two key synthetic steps, i.e. connection and annelation. The most efficient approaches to $[n]$ helicenes use multiple annelations, forming two or more rings in one synthetic step; however, relatively few annelation reactions have been implemented effectively.

\subsubsection{Photochemical Syntheses}

Oxidative photocyclization of stilbene to phenanthrene, which was discovered in 1960, was fast applied to the synthesis of [7]helicene by Martin and coworkers in $1967[26,44,45 \mathrm{j}$. This approach was extended to the syntheses of long $[n]$ helicenes $(n \leq 14)$ and $[n]$ thiahelicenes $(n \leq 15)$, using both mono- and diannelations. Numerous $[n]$ helicenes $(n \leq 13)$ and $[n]$ thiahelicenes $(n \leq 13)$ were obtained in non-racemic form via the following methods: (1) seeded crystallization of conglomerate (e.g. [7]-, [8]-, and [9]helicene) [46, 47], (2) resolution by chromatography (e.g. [13]thiahelicene) [48] and (3) photocyclization from a resolved precursor (e.g. [13] helicene from hexahelicene-2-carboxylic acid) [49]. The oxidative photocyclization of stilbenes is still the method of choice for the preparation of selected $[n]$ helicenes and their heteroatom analogs [50-58].

Vollhardt's group adopted the cobalt-catalyzed photochemical cyclotrimerization of alkynes for the rapid construction of a novel class of helicenes, helical

Figure $15.1[n]$ Helicenes 

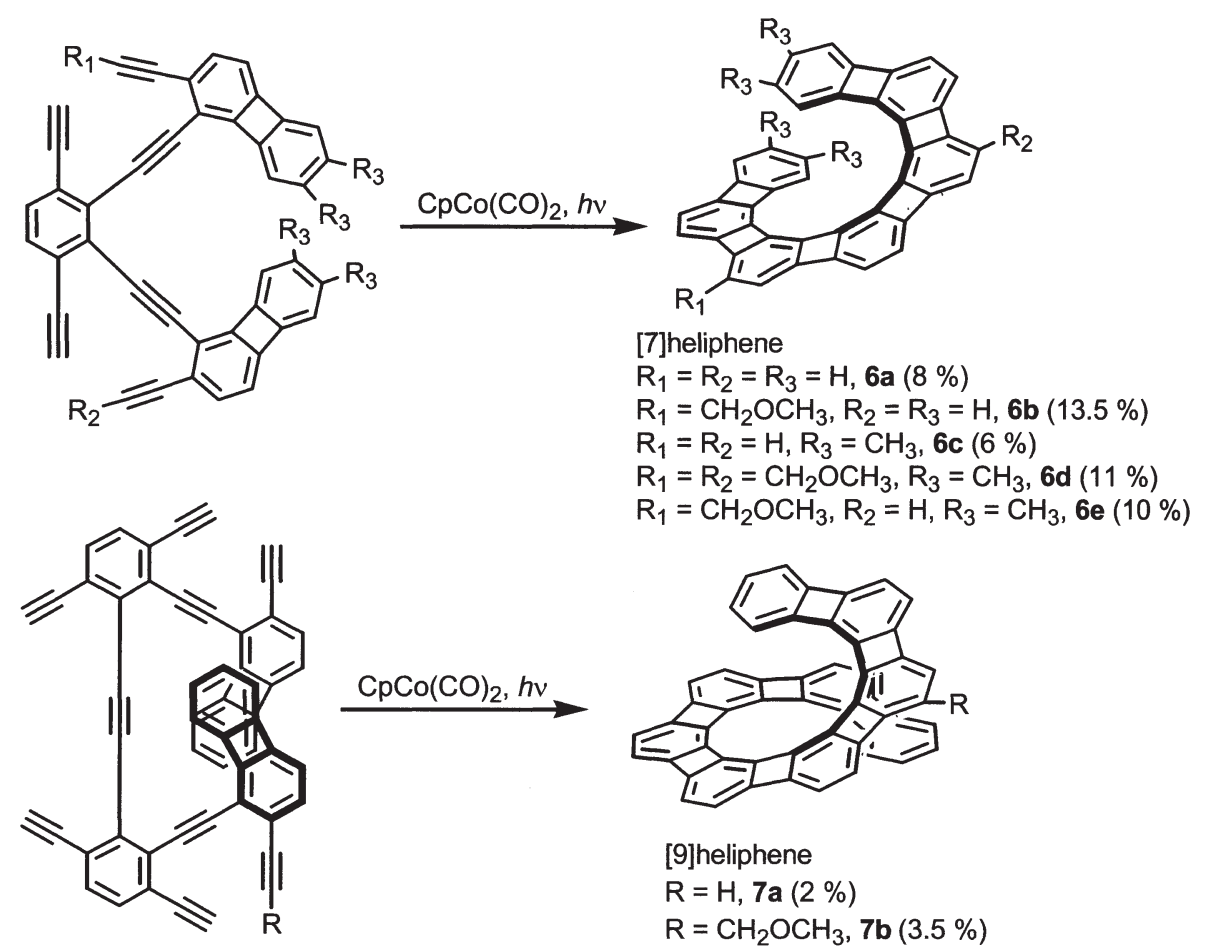

Figure 15.2 Photochemical syntheses of [ $n$ ] heliphenes via di- and triannelation.

$[n]$ phenylenes or " $[n]$ heliphenes," consisting of alternating $[n]$ benzene units fused with $[n-1]$ cyclobutadiene rings $[59,60]$. This class of helicenes have a significantly increased helical radius compared with benzene-based helicenes. The synthesis is based on di- and triannelations of the corresponding oligoynes, providing [7]heliphenes (6) and [9]heliphenes (7) in $\sim 10 \%$ and $2-3.5 \%$ yields, respectively (Figure 15.2). In the case of triannelation, nine rings were formed in one step, including six cyclobutadiene rings with an estimated strain of $300 \mathrm{kcal} \mathrm{mol}^{-1}$ ! This is the only report of photochemical triannelation leading to helicene-like skeleton.

Molecular geometries from X-ray structures for $[n]$ heliphenes with $n$ up to 8 indicate significant bond fixation in the $\pi$-system. However, significant electron delocalization was found $[59,60]$. Based on the linear plot of $\lambda_{\max }$ vs $1 /(n+0.5)$, the optical band gaps $E_{\mathrm{g}}=2.2 \mathrm{eV}(n=2-9)$ or $E_{\mathrm{g}}=2.1 \mathrm{eV}(n=4-9)$ may be estimated for the corresponding polyheliphene. Analogous plots of $\lambda_{\max }$ vs $1 / n$ for $[n]$ helicenes $(n$ $=6-9)$ and $[n]$ thiahelicenes $(n=5,7,9,11)$ give somewhat higher $E_{\mathrm{g}}=2.5 \mathrm{eV}\left[R^{2}\right.$ $=0.975)$ and $E_{\mathrm{g}}=2.4 \mathrm{eV} /\left(R^{2}=0.984\right)$, respectively. Heliphenes possess surprisingly low barriers for racemization and could not be resolved (see Section 15.3).

\subsubsection{Non-photochemical Syntheses}

Syntheses of $[n]$ helicenes (and $[n]$ thiahelicenes) via oxidative photocyclizations of stilbenes have serious constraints. They must be carried out in dilute solutions $(\sim 1$ $\mathrm{mM})$ and the functional groups that significantly affect relaxation of the singlet excited states of stilbenes such as bromo, iodo, keto, amino and nitro, are typically not compatible; for longer helicenes, problems with regioselectivity of photocyclization may be encountered [61]. These limitations have spurred the recent developments of nonphotochemical syntheses for efficient preparation of highly functionalized, nonracemic helicenes.

For nonphotochemical syntheses, there are three major approaches: (1) annelation of racemic intermediate leading to racemic $[n]$ helicene, followed by resolution, (2) annelation of nonracemic intermediate giving nonracemic $[n]$ helicene and (3) asymmetric synthesis, i.e. annelation of racemic intermediate in the presence of chiral reagent, catalyst or auxiliary.

To date, the reported nonphotochemical syntheses of racemic and enantiopure $[n]$ helicenes are limited to $n=9$ and 8, respectively [62,63]. Recently, asymmetric syntheses of $[n]$ helicenes with $n$ up to 11 were developed in our laboratory [64].

\section{Annelation of racemic intermediate leading to racemic $[n]$ helicene}

Larsen and Bechgaard reported the nonphotochemical synthesis of racemic [5]- and [9] thiahelicenes, relying on monoannelations of stilbene precursors [62]. Electrochemical or chemical $\left(\mathrm{FeCl}_{3}\right)$ oxidation was used in place of usual photooxidation, to provide thiahelicenes in 20-65\% yields. For example, racemic [9] thiahelicene 9 was obtained in $\sim 60 \%$ yield from stilbene 8 by oxidation with $\mathrm{FeCl}_{3}$ in methylene chloride (Figure 15.3); a similar result was obtained by classical photooxidation of stilbene 8 [51].

Annelations via Diels-Alder reaction were employed by Katz and coworkers to develop exceedingly efficient methods for multi-gram scale syntheses of $[n]$ helicenes with $n$ up to 7. Efficient resolutions were carried out via functionalization with the camphanate ester derivatives and then separation of diastereomers by column chromatography $(>98 \% d e)$. This synthetic approach may be illustrated by the synthesis of enantiopure [7]thiahelicene 10 [65]. Notably, the Diels-Alder diannelation and aromatization gives racemic $\mathbf{1 0}$ in $95 \%$ yield. Resolution with camphanate tetraester provides enantiopure 11 (Figure 15.4).
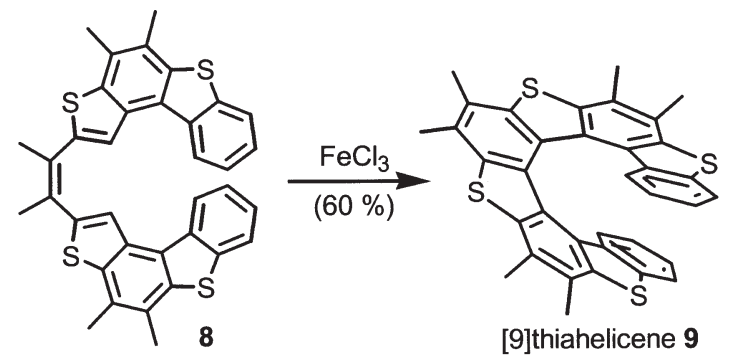

Figure 15.3 Synthesis of [9]thiahelicene 9 . 


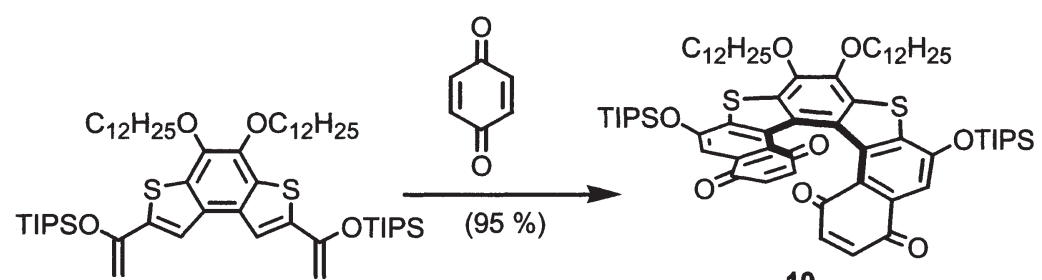

10

10

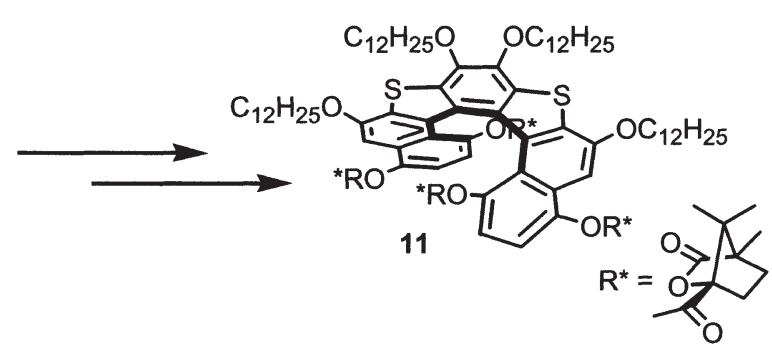

Figure 15.4 Synthesis of [7]thiahelicene 11 via Diels-Alder diannelation.

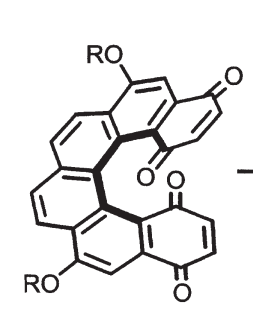

$\mathrm{R}=\left(\mathrm{CH}_{2}\right)_{2} \mathrm{O}\left(\mathrm{CH}_{2}\right)_{3} \mathrm{CH}_{3}$ [6] helicene $(M)-12$

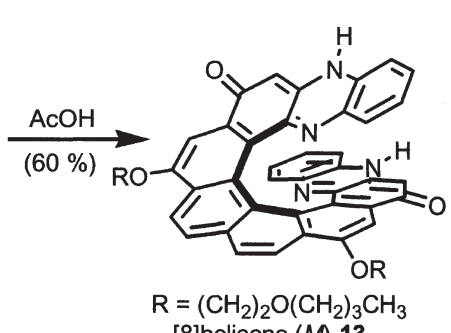

[8]helicene $(M)-13$
Figure 15.5 Synthesis of $(M)$-[8]helicene 13 from enantiopure [6]helicene derivative

Analogous Diels-Alder diannelations of divinylnaphthalenes and divinylphenanthrenes or their heteroatom analogs with 1,4-benzoquinone yielded series of $[n]$ helicenebisquinones, $[n]$ heterohelicenebisquinones, and their derivatives; the material properties of their aggregates have been extensively studied [66-69].

Elaboration of enantiopure $(M)$-[6]helicenebisquinone 12 into $(M)$-[8]helicene 13 with complete transfer of ee was reported (Figure 15.5) [63]. [8]Helicene 13 is the longest enantiopure helicene prepared via nonphotochemical synthesis.

Annelations via Friedel-Crafts acylation were applied to racemic syntheses of $[n]$ helicenes with $n$ up to 6 . The 12-step synthesis of [6]helicene (1) by Newman and Lednicer employed stepwise diannelation, followed by oxidative aromatization and then resolution with the complex of a chiral $\pi$-acceptor, $\alpha-2,4,5,7$-tetrani-tro-9-fluorolideneaminooxypropionic acid (TAPA) and $\mathbf{1}$ [25]. The one-step diannelation was ubiquitously applied to syntheses of triarylamine [4]helicenes, e.g. 14-16, by Hell-
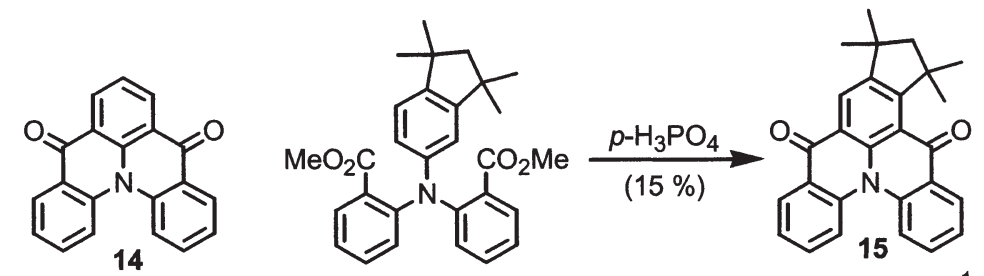

$\left(16.1 \mathrm{kcal} \mathrm{mol}^{-1}\right)$
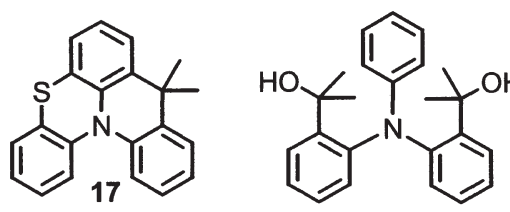

$\mathrm{CH}_{3} \mathrm{SO}_{3} \mathrm{H}$

$(92 \%)$

$\left(28.4 \mathrm{kcal} \mathrm{mol}^{-1}\right)$
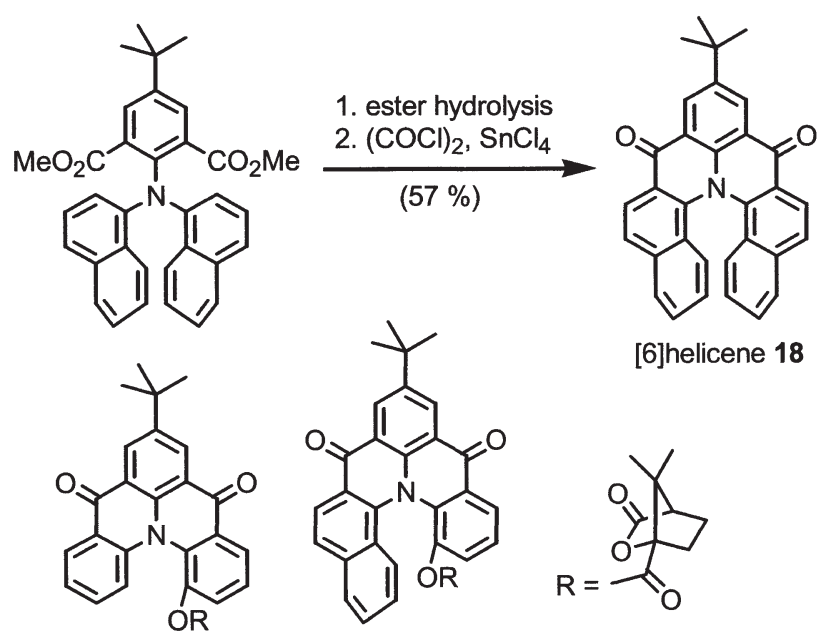

[4]helicene 19

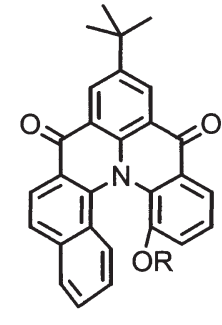

[5]helicene 20

Figure 15.7 Synthesis and resolution of triarylamine [n]helicenes.

winkel and Schmidt (Figure 15.6) [70]. Diastereotopicity of the methyl groups in 1517 was used to determine barriers for inversion (racemiza-tion) by ${ }^{1} \mathrm{H}$ NMR spectroscopy. For 5,5,9,9-tetramethyl-5H,9H-quino[3,2,1-de]acridine (16), Fox et al. reported an improved procedure, using $10 \% \mathrm{P}_{2} \mathrm{O}_{5}$ in methanesulfonic acid at room temperature as a mild cyclodehydrating reagent/solvent, to give a $92 \%$ yield for one-step diannelation (Figure 15.6) [71].

Hellwinkel and Schmidt's approach was recently extended by Venkataraman and coworkers to triarylamine [ $n$ ] helicenes, with $n \leq 6$, e.g. 18 [72]. Sterically hindered 
[4]helicene 19 and [5]helicene 20 were resolved, using Katz's camphanate ester derivatives (Figure 15.7) [73].

Other annelation reactions leading to racemic $[n]$ helicenes with $\mathrm{n} \geq 6$ include carbenoid coupling providing the parent [7] helicene [74].

\section{Annelation of nonracemic intermediate giving nonracemic [ $n$ ]helicene}

Several methods for the transfer of center or axial chirality into helical chirality have been described. In many cases, practically complete transfer of enantiomeric excess was observed.

An interesting example of the transfer of center chirality to helicity is the work by Ogawa et al., based on an asymmetric aromatic oxy-Cope rearrangement to provide nonracemic [5] helicenes (Figure 15.8) [75]. The starting material with center chirality, bicyclo[2,2,2]ketone $(-)-21(>98 \% e e)$, was obtained by enzymatic resolution. In the annelation step, the phenanthrene derivative was subjected to aromatic oxyCope rearrangement, to afford a pentacyclic product in $47 \%$ yield. The corresponding [5] helicene 22 was obtained in $7 \%$ overall yield ( $>98 \%$ ee) after six steps.

Two approaches to nonracemic [5]helicenes, starting from axially chiral binaphthyls, provided an early stereochemical correlation between axial and helical chiralities. The correlation was based on comparison of the signs of optical rotations; the absolute configurations of binaphthyls were obtained from chemical correlation.

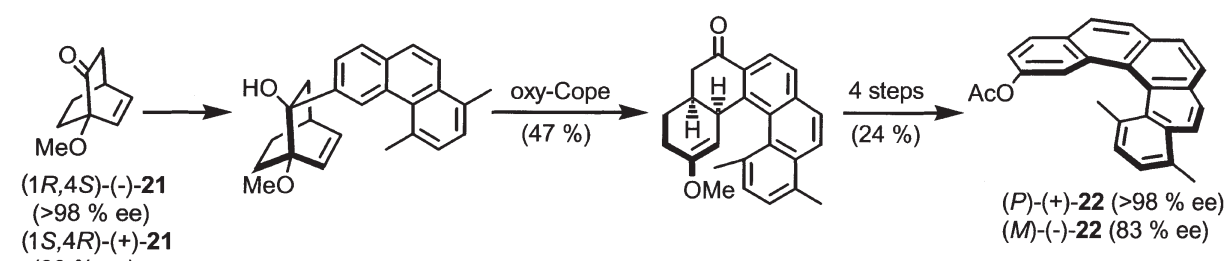
(1S,4R)-(+)-21

Figure 15.8 Synthesis of nonracemic [5]helicene 22 via oxy-Cope rearrangement.

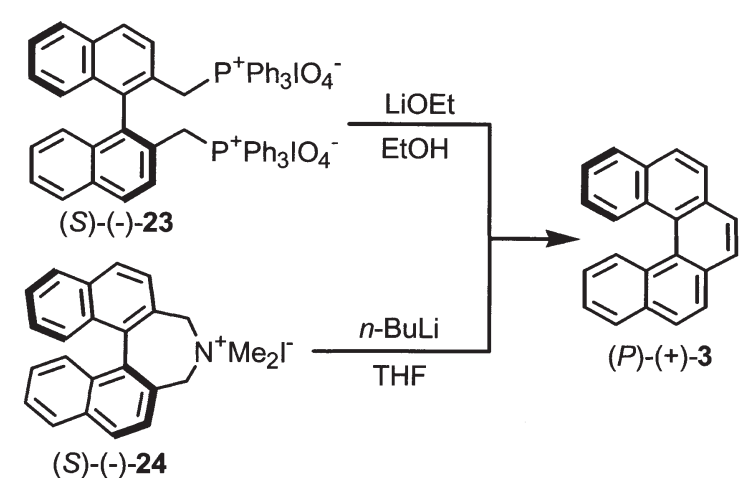

Figure 15.9 Syntheses of nonracemic [5]helicene 3: stereochemical correlation between axial and helical chiralities.
Starting from optically enantiopure derivatives of $(S)-(-)$-binaphthyl, annelation via either oxidative cyclization of the 2,2'-bis-phosphonium periodate $\mathbf{2 3}$ or Stevens rearrangement of quaternary ammonium salt $\mathbf{2 4}$ gave enantiopure $(P)-(+)-[5]$ helicene $\mathbf{3}$ (Figure 15.9) [76, 77].

The axial-to-helical configuration transfer was more recently applied to [7]thiahelicenes 29 and 33, using McMurry reaction of dialdehyde or diketone in the annelation step, to form the central benzene ring $[78,79]$. Both enantiomers of helicenes could be obtained.

In the synthesis of 29 [78], axially chiral precursor was obtained via biaryl coupling between benzodithiophenes with chiral oxazoline [derived from $(S)$-valinol] as an auxiliary, e.g. Stille cross-coupling of $\mathbf{2 5}$ and $\mathbf{2 6}$ provided bis(benzodithiophene) 27 in $68 \%$ yield with $49 \%$ de (Figure 15.10). Although the diastereomers were not separable by silica gel column chromatography, crystallization of diastereomers from hexane-ethyl acetate gave crystals with an $S$-axial configuration. Both enantiomers were obtained according to the following sequence: ring opening and acetylation the bis(oxazolines), separation of diastereomers by silica gel chromatography, reduction with $\mathrm{LiAlH}_{4}$ to diol and oxidation with PCC to dialdehyde 28. The intramolecular McMurry reaction $\left(\mathrm{TiCl}_{3}-\mathrm{DME}_{1.5} / \mathrm{Zn}-\mathrm{Cu}\right)$ of enantiomeric pure dialdehyde gave the enantiopure [7] thiahelicene 29 (>99\% ee) (Figure 15.10).

In the synthesis of $\mathbf{3 3}$ (Figure 15.11) [79], hexathiophene $\mathbf{3 0}$ was converted to racemic diketone $\mathbf{3 1}$ and then kinetic resolution of diketone $\mathbf{3 1}$ was carried out using $(-)$ - $B$-chlorodiisopinocampheylborane [(-)-DIP-chloride]. The unreacted (-)-diketone 31 was isolated in $\sim 40 \%$ yield. The reduction product, mono-alcohol 32, gave (+)-diketone 31 in $\sim 40 \%$ yield based upon racemic diketone. The intramolecular McMurry reaction of diketone 31, using $\mathrm{TiCl}_{3}-\mathrm{Zn}-\mathrm{DME}$ (instant method), gave [7]helicene 33 in $17-63 \%$ isolated yield. [7]Helicene diol 35 (probably the transisomer) was formed in complementary yields, so the overall for annelation to [7]helicene was about $70 \%$. The yields are relatively high in view of steric hindrance of the diketone and the presence of both TMS- and Br-functionality. Removal of the TMS groups gives [7]helicene 34; racemic 34 crystallizes as either conglomerate or racemic compound, depending on the conditions of crystallization (Figure 15.11).

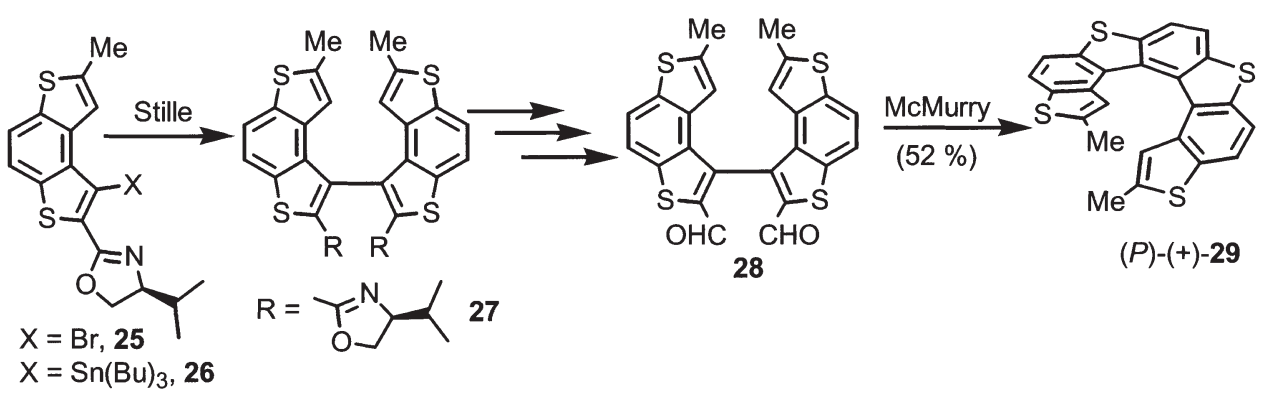

Figure 15.10 Synthesis of enantiopure [7]thiahelicene via McMurry annelation of dialdehyde. 


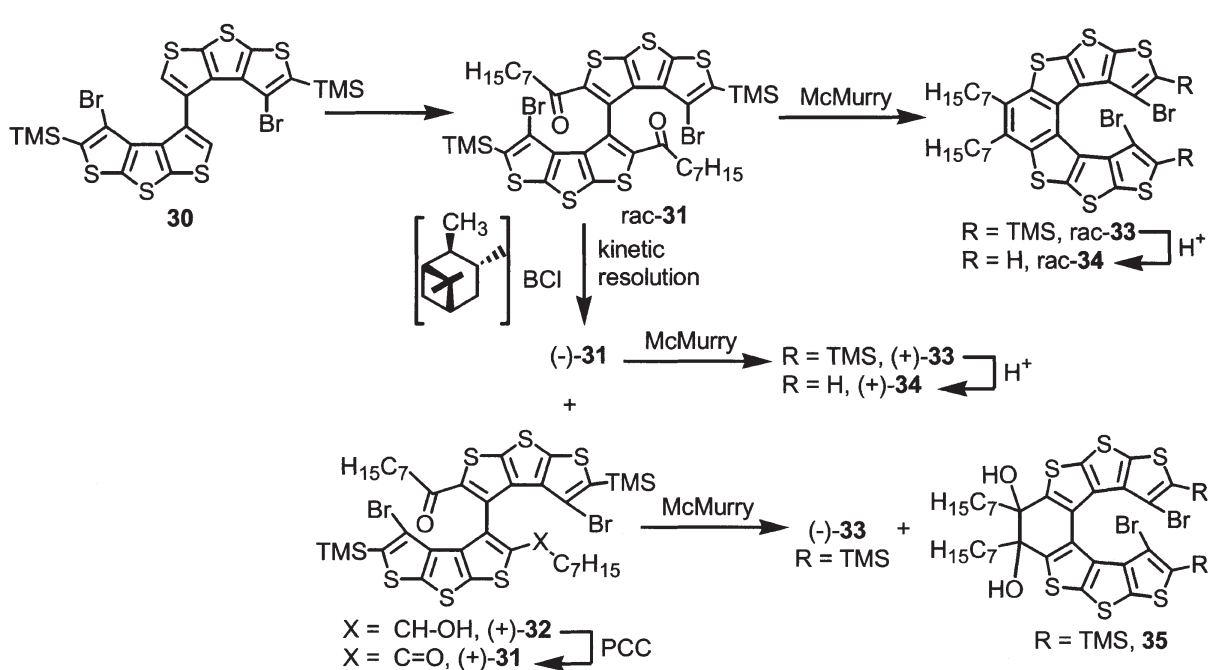

Figure 15.11 Synthesis of highly functionalized enantiopure [7]thiahelicenes via kinetic resolution of axially chiral diketones and McMurry annelation.

Based on X-ray crystallographic determinations of the absolute configurations for (+)-enantiomers of the diketone and the [7] helicene 34, stereochemical correlation between the $R$ axial chirality of the diketone and the $M$ helical chirality of the [7]helicene was unequivocally established [79]. Enantiopure [7]helicene $\mathbf{3 3}$ was functionalized for the design of organic chiral glasses with strong chiroptical properties (Section 15.4) and for homologation to higher $[n]$ helicenes.

\section{Asymmetric synthesis}

To date, only three approaches to nonphotochemical asymmetric syntheses of $[n]$ helicenes with $n \geq 6$ have been reported. The key step in such syntheses is annelation of racemic intermediate in the presence of a chiral reagent, catalyst or auxiliary.

Carreño et al. described asymmetric syntheses of [5] helicenequinone and [7]helicenebisquinone [80, 81]. This approach is illustrated for [7]helicenebisquinone $\mathbf{3 6}$ [80]. The key step was diannelation based on the Diels-Alder reaction between 3,6divinyl-1,2,7,8-tetrahydrophenanthrene and enantiopure ( $S, S)$-2-( $p$-tolylsulfinyl)-1,4benzoquinone; subsequent elimination and aromatization steps gave $\mathbf{3 6}$ with high ee (Figure 15.12).

Another important approach to the synthesis of helicenes is the convergent route based on energy-rich cis,cis-dienetriynes and their $\mathrm{Ni}(0)$-catalyzed $[2+2+2]$-cycloisomerization, which was reported by Stara and coworkers $[82,83]$. The potential of this methodology was demonstrated by the synthesis of functionalized [5]-, [6]-, and [7] helicenes in $60-83 \%$ yield. However, only one example of asymmetric synthesis

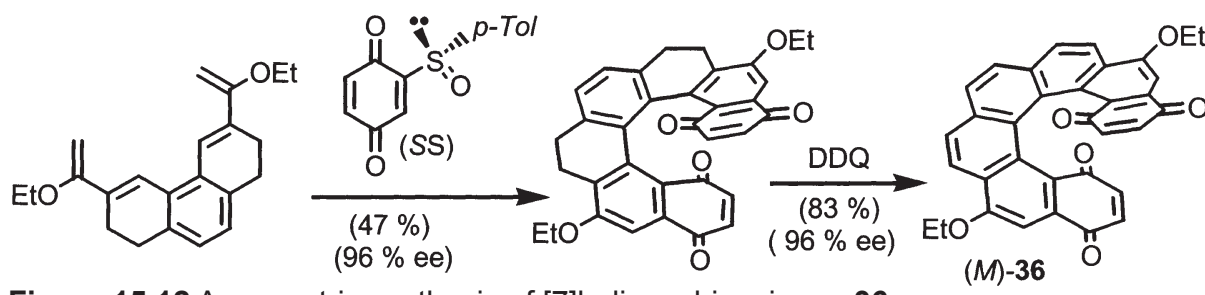

Figure 15.12 Asymmetric synthesis of [7]helicenebisquinone 36 .

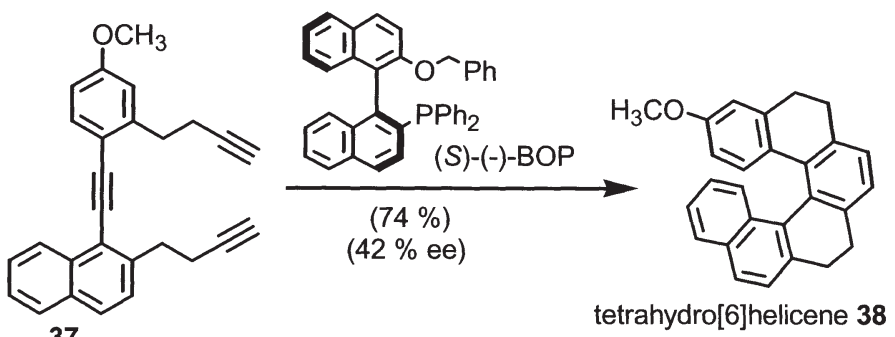

etrahydro[6]helicene 38

Figure 15.13 Nickel(0)-catalyzed asymmetric synthesis of tetrahydro[6]helicene $\mathbf{3 8}$.

using this approach was reported, i.e. the $\mathrm{Ni}(0)$-catalyzed annelation of triyne $\mathbf{3 7}$ to the corresponding tetrahydro[6]helicene $38(74 \%, 42 \%$ ee $)$ in the presence of a chiral ligand [(S)-(-)-BOP] (Figure 15.13) [83].

A new class of $\beta$-oligothiophenes, in which $n$ thiophenes are helically annelated to form $[n]$ helicene, was developed recently [64, 84-87]. Such carbon-sulfur $[n]$ helicenes are fragments of an unusual polymer such as carbon-sulfur $\left(\mathrm{C}_{2} \mathrm{~S}\right)_{\mathrm{n}}$ helix (Figure 15.14). The sulfur-rich molecular periphery is expected to facilitate multiple S-S short contacts that have been associated with improved transport properties in sulfur-containing molecular solids. The carbon-carbon frameworks in $\left(\mathrm{C}_{2} \mathrm{~S}\right)_{\mathrm{n}}$ helices are formally cross-conjugated, in contrast to electron-delocalized $\pi$-conjugated systems of $\alpha$-oligothiophenes. However, the questions of electron delocalization vs. localization and the magnitude of the band gap in the $\left(\mathrm{C}_{2} \mathrm{~S}\right)_{\mathrm{n}}$ helix require the synthesis of a series of sufficiently long oligomers, to account for the effect of helical distortion on the electronic structure. The synthesis of nonracemic $[n]$ helicenes will provide an insight into the relationship between chiral properties and cross-conjugation. This is important for the development of materials with strong chirality, wide band gap and optical transparency.

Iterative racemic synthesis and asymmetric synthesis of the [7] helicene $\mathbf{4 0}$ and resolution of its TMS-free derivative 41 were reported [84, 85]. The racemic synthesis was based on iterative alternation of two steps: $\mathrm{CC}$ bond homocouplings between the ( $\beta$-positions of thiophenes and annelation between the $\alpha$-positions of thiophenes (Figure 15.15). 
Figure 15.14 Carbon-sulfur $\left(\mathrm{C}_{2} \mathrm{~S}\right)_{n}$ helix illustrated as stick and space-filling plots for oligomers of $\mathbf{2 1}$ helically annelated thiophenes.
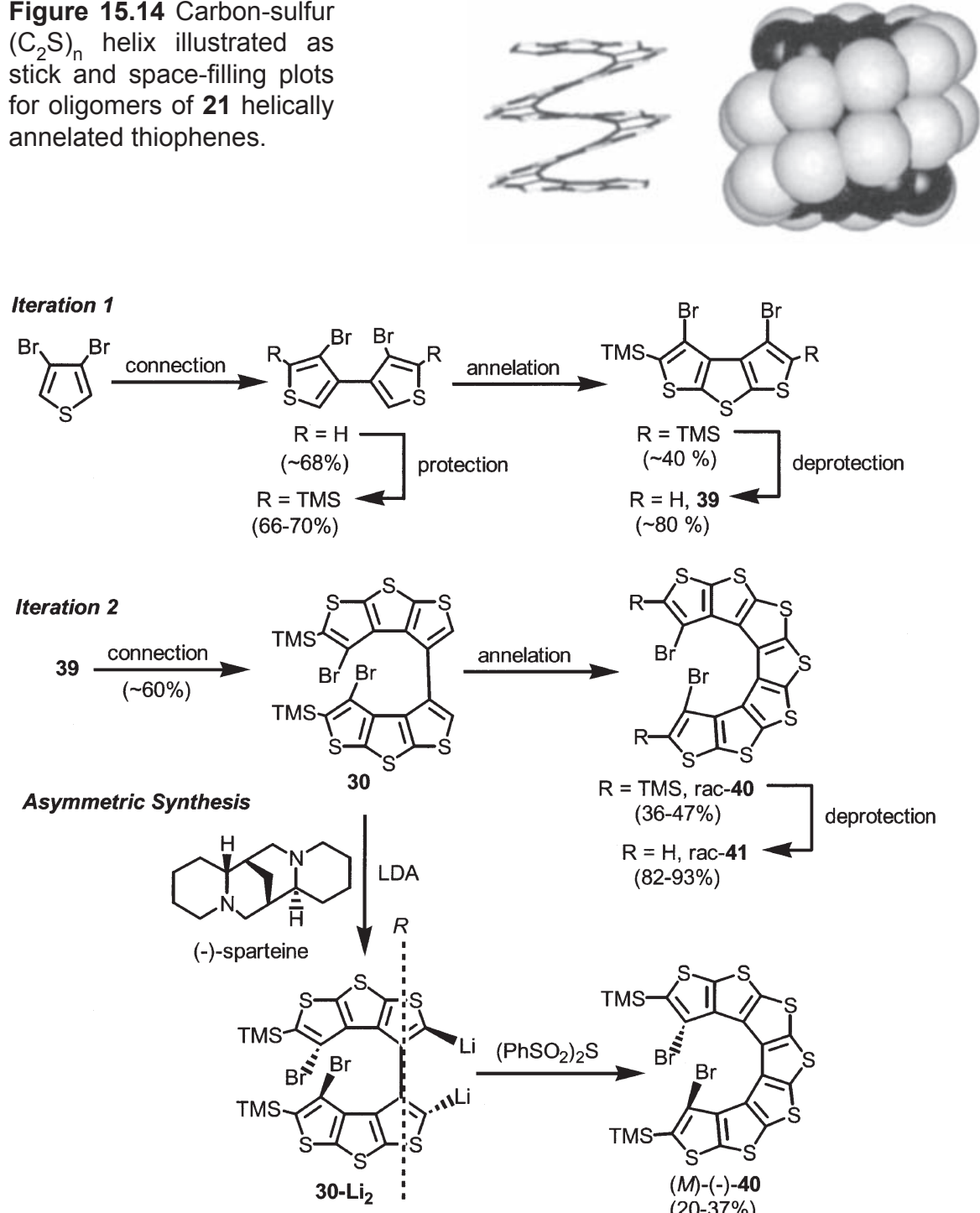

Figure 15.15 Iterative synthesis and asymmetric synthesis of carbon-sulfur [7]helicene $\mathbf{4 0 .}$

Asymmetric synthesis relied upon the use of $(-)$-sparteine in the final annelation step leading to $\mathbf{4 0}$ (Figure 15.15). Mechanistic studies revealed that (-)-sparteinemediated stereoinduction was associated with kinetic resolution in the incomplete formation of dilithiated intermediate $30-\mathrm{Li}_{2}$ and the reaction of diastereomeric complexes of $30-\mathrm{Li}_{2}$ with bis(phenylsulfonyl) sulfide [85]. The absolute configura-

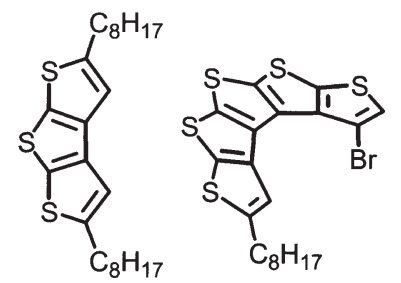

42

$\mathrm{C}_{8} \mathrm{H}_{17}$
43

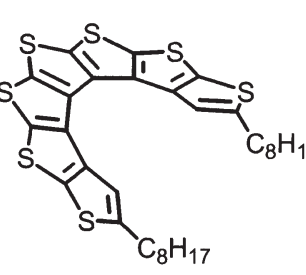

44

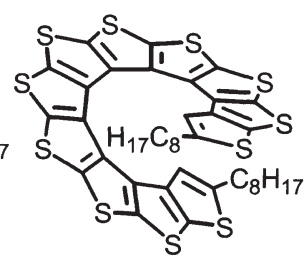

45
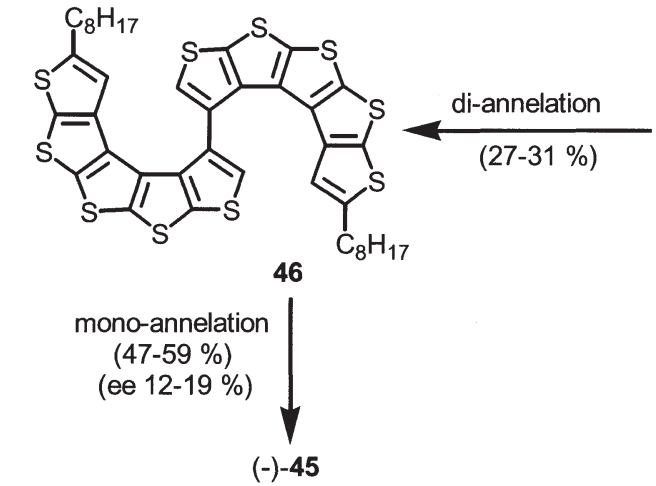

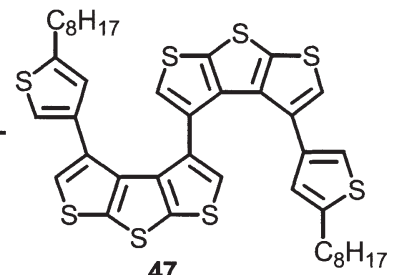

47

tri-annelation (1.3-3\%) (ee $11-17 \%)$

$(+)-45+46$
Figure 15.16 Structures of trithiophene 42, [5] helicene 43, [7] helicene 44, [ $n$ ] helicene 45 and (-)-sparteine-mediated asymmetric synthesis of [11] helicene 45. LDA (monoand triannelation) and $n$-BuLi (diannelation) were used as bases.

tion of the predominant (-)-enantiomer was established as $M$ by vibrational circular dichroism (CD) studies [86]. This stereoinduction involving axial $R$-configuration was consistent with the results of asymmetric synthesis of tetraphenylenes via the $\mathrm{Cu}$ (II) oxidation of 2,2'-dilithiobiaryls (Section 15.2.3). Finally, resolution with menthol-based siloxanes was implemented to obtain both enantiomers of the TMSfree [7] helicene 41.

Recently, series of carbon-sulfur $[n]$ helicenes substituted with $n$-octyl groups at the $\alpha$-positions of the terminal thiophene rings were prepared (Figure 15.16) [64, 87]. The helical structures of [7]helicene 44 and [11]helicene 45 were confirmed by X-ray crystallography. Multiple short S-S contacts were found, especially for racemic [11]helicene 45. Asymmetric synthesis of [11] helicene $\mathbf{4 5}$ provided enantiomeric excess of either the (-)- or the $(+)$-enantiomer for the monoannelation or, unprecedented, triannelation approach (Figure 15.16). Also, selective diannelation of octathiophene 47, followed by monoannelation of decathiophene 46, provided an efficient synthetic route to (-)-[11] helicene 45 , avoiding protection/deprotection steps [64].

UV-Vis absorption studies revealed that the helical oligothiophenes $\mathbf{4 4}$ and $\mathbf{4 5}$ had identical absorption onset but significantly red shifted to the onset for the planar trithiophene 42, This provided an estimate for the optical band gap, $E_{\mathrm{g}} \approx 3.5 \mathrm{eV}$, of the 
$\left(\mathrm{C}_{2} \mathrm{~S}\right)_{n}$ helix polymer and indicated that the electron localization occurs already for $n \leq 7$ [64]. These results are in contrast to electron delocalization in $[n]$ heliphenes, $[n]$ helicenes, and $[n]$ thiahelicenes, which possess much lower $E_{\mathrm{g}}$ values of 2.1-2.5 $\mathrm{eV}$. These results are consistent with cyclic voltammetric data. $[n]$ Helicenes 40, 44, and $\mathbf{4 5}$ showed reversible cyclic voltammetric waves (1.2-1.3 V vs. SCE); the second oxidation wave for $\mathbf{4 0}$ was found at $\sim 1.8 \mathrm{~V}$, i.e. at a significantly more positive potential $[64,85]$.

\subsection{2}

\section{Double Helicenes and Chiral Polycyclic Aromatic Hydrocarbons}

Double and triple helicenes are $\pi$-conjugated molecules, which consist of two or three annelated helicene-like subunits. Such structures may also be considered as examples of chiral polycyclic aromatic hydrocarbons (PAHs).

The first double helicenes, consisting of head-to-tail annelated [6] helicenes, were prepared by oxidative photocyclization of stilbenes to helicenes [21]. Recently, double helicene 48, in which two benzene rings are shared by [5]- and [7]helicene, was prepared via nonphotochemical Pd-catalyzed cyclotrimerization of 3,4-didehydrophenanthrene derived from 47 (Figure 15.17) [88]. The ${ }^{1} \mathrm{H}$ NMR spectrum for racemic 48 showed better agreement with the calculated spectrum for the diastereomer with homochiral versus heterochiral helicenes. The characterization of double helicenes did not include X-ray crystallography [21,88].

Recently, a conjoined double helicene, in which two hydrazine-based [5]helicenes are highly annelated in their mid-sections, was reported [89]. The conjoined double helicene 51- $\boldsymbol{D}_{2}$ possesses two homochiral hydrazine-based [5] helicene-like fragments annelated in their mid-sections. The synthesis of conjoined double helicene $\mathbf{5 1 - \boldsymbol { D } _ { \mathbf { 2 } }}$ from 49 consists of two annelation steps: (1) Friedel-Crafts diannelation to provide pentacyclic diamine $\mathbf{5 0}$ and (2) one-step oxidative coupling forming one $\mathrm{CC}$ and two NN bonds [90], to give dodecacyclic structure 51- $\boldsymbol{D}_{\mathbf{2}}$ (Figure 15.18).

The Friedel-Crafts diannelation in the first step was based on Hellwinkel and Schmidt's methodology for [4]helicenes, except for the use of alkenes instead of alcohols as the precursors to the intermediate carbocations (Section 15.2.1) [70].

In the second step, the chiral $D_{2}$-symmetric structure $\mathbf{5 1 - D _ { 2 }}$ is the kinetic product, which may be irreversibly converted to its achiral $C_{2 \mathrm{~h}}$-symmetric diastereomer 51$\boldsymbol{D}_{\mathbf{2 h}}$ (Figure 15.19). Mechanistic studies indicated that oxidation of achiral diamine

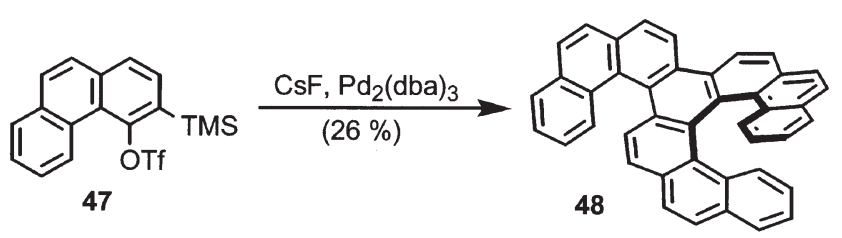

Figure 15.17 Palladium-catalyzed cyclotrimerizations of didehydrophenanthrene leading to double helicenes.

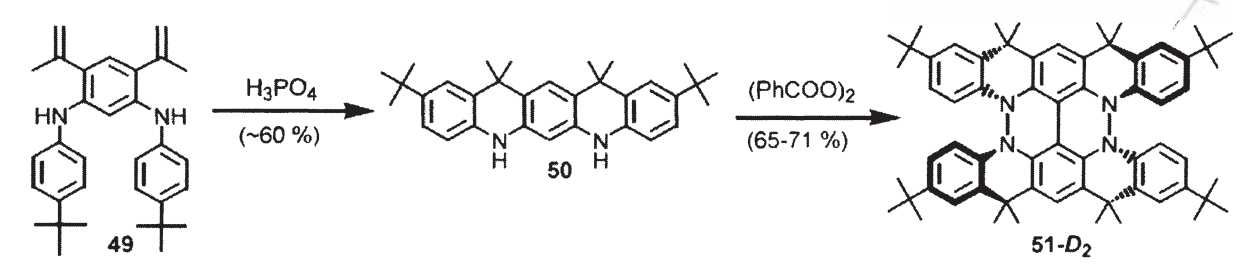

Figure 15.18 Synthesis and X-ray structure of conjoined double helicene $51-D_{2}$. Each of the two homochiral [5]helicene-like fragments is shown in stick-and-ball format.

50 to chiral $\mathbf{5 1 - D _ { 2 }}$ occurs via achiral tetraamine $\mathbf{5 2}$, that is, the $\mathrm{CC}$ bond homocoupling occurs first. Upon partial oxidation of 50, tetraamine $\mathbf{5 2}$ was isolated in 59-

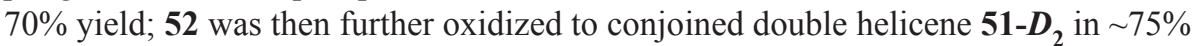
yield. Notably, conjoined double helicene $\mathbf{5 1 - D _ { 2 }}$ could be reduced to tetraamine $\mathbf{5 2}$. Thus, chiral $\mathbf{5 1}-\boldsymbol{D}_{\mathbf{2}}$ and achiral $\mathbf{5 2}$ are interconvertible via redox cleavage and formation of the NN bonds of the hydrazine moieties. The structures of all key compounds $\mathbf{5 0}, \mathbf{5 1}-\boldsymbol{D}_{\mathbf{2}}$ and $\mathbf{5 2}$ were established by X-ray crystallography $[89,91]$.

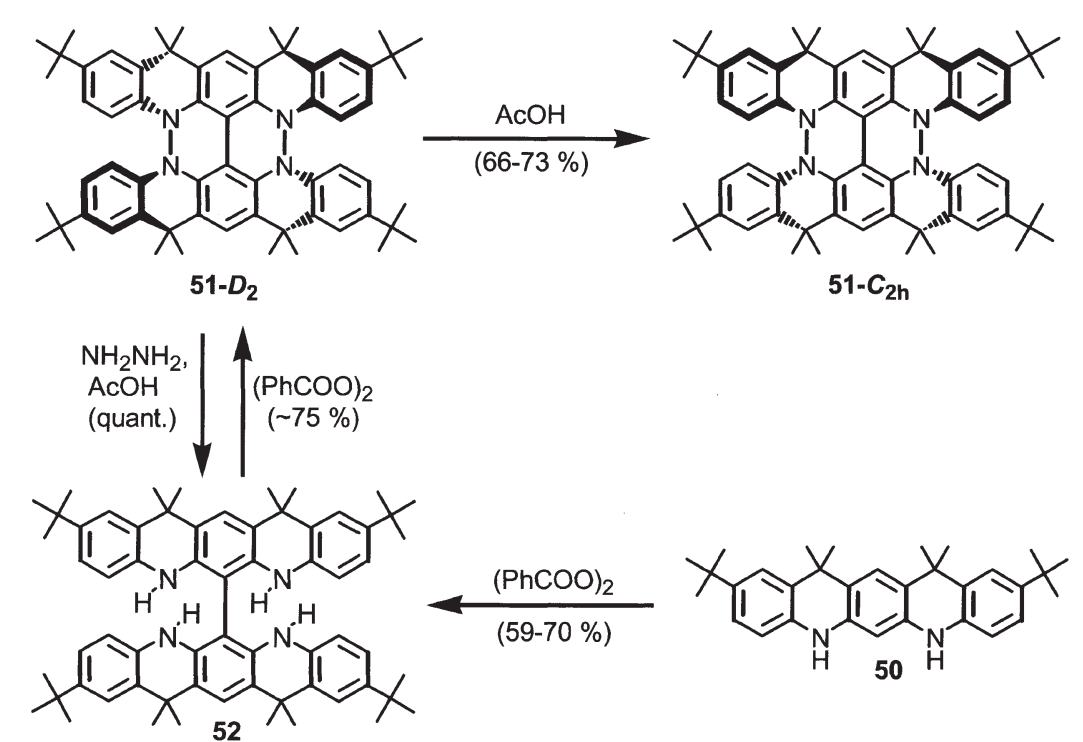

Figure 15.19 Stepwise synthesis of $51-D_{2}$ and its diastereomer $51-D_{2 h}$. 


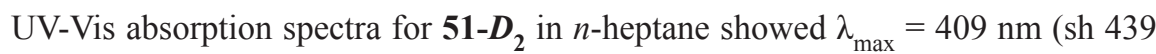
$\mathrm{nm}$ ), which was significantly red shifted compared $\lambda_{\max }=275 \mathrm{~nm}(\mathrm{sh} 333 \mathrm{~nm})$ for diamine 50. Crystalline 51- $D_{2}$ showed blue-green fluorescence; in $n$-heptane, a blue fluorescence with quantum efficiency $\Phi_{\mathrm{F}} \approx 15 \%$ at $\lambda_{\text {max }}^{\mathrm{em}}=472 \mathrm{~nm}$ (excitation at $\lambda^{\mathrm{exc}}=289$ and $409 \mathrm{~nm}$ ) was found.

Extended $C_{3}$-symmetric PAHs, which may be viewed as graphite disks, have been prepared via efficient oxidative cyclodehydrogenations by Mullen and coworkers [92]. When the bay areas of such PAHs possess overcrowded hydrogens or when they correspond to $[n]$ helicene-like units, the possibility of chiral conformations with significant barriers for racemization and/or conversion between diastereomers arises. Hexabenzotriphenylene $\mathbf{5 3}$ is the best studied example of chiral, overcrowded PAHs with significant steric congestion of the bay hydrogens. Hexabenzotriphenylene $\mathbf{5 3}$ may be viewed as a triple helicene, composed of three [5]helicene units, sharing the triphenylene core. X-ray structures for both chiral diastereomers, $53-D_{3}$ and $\mathbf{5 3}-C_{2}$ $\left(D_{3}\right.$ - and $C_{2}$-symmetric, respectively) were determined [93, 94]. 53- $C_{2}$, which is less

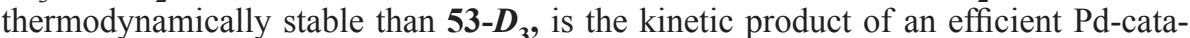
lyzed cyclotrimerization of 9,10-didehydrophenanthrene (Figure 15.20) [95]. Another recent example of a triple helicene, with three [5] helicene-like units, is an extended derivative of symmetrical triindole, a triaza analog of truxene [96].

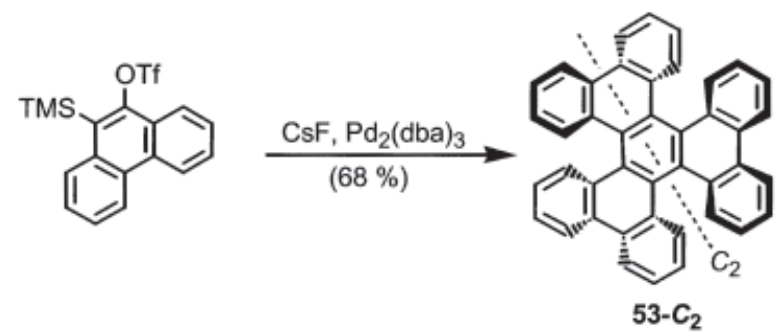

Figure 15.20 Palladium-catalyzed cyclotrimerizations of didehydrophenanthrene leading to triple helicene.

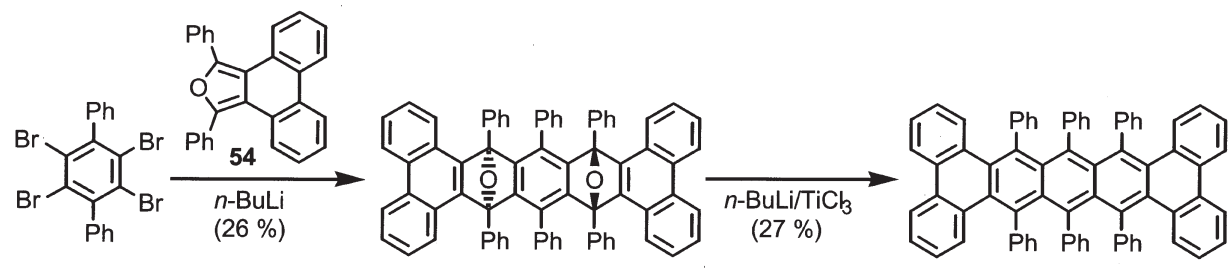

55

Figure 15.21 Synthesis of PAH with a screw-type helicity
An overcrowded PAH, 9,10,11,20,21,22-hexaphenyltetrabenzo[a,c,l,n]pentacene (55), showed an interesting screw-type helicity (Figure 15.21) [97]. An end-to-end twist of $144^{\circ}$ was estimated from the X-ray structure of 55. Pentacene 55 was prepared by the reaction of 1,3-diphenylphenanthro[9,10-c]furan $\mathbf{5 4}$ with the bisaryne equivalent generated from 1,2,4,5-tetrabromo-3,6-diphenylbenzene in the presence of $n$-butyllithium, followed by deoxygenation of the double adduct with low-valent titanium. Pentacene $\mathbf{5 5}$ could be resolved by chromatography on a chiral support, but it racemized slowly at room temperature $\left(t^{1 / 2} \approx 9\right.$ h at $\left.25^{\circ} \mathrm{C}\right)$.

\section{2 .3}

\section{Tetraphenylenes and $\pi-C o n j u g a t e d ~ D o u b l e ~ H e l i c e s$}

Tetra-o-phenylene (tetraphenylene, Figure 15.22) is an achiral tube-shaped molecule ( $D_{2 \mathrm{~d}}$ point group). However, tetraphenylene can be readily desymmetrized, by substitution or annelation, to produce a chiral $\pi$-conjugated system with an extraordinarily high barrier for racemization (Section 15.3). In the X-ray structures of tetraphenylenes, the dihedral angles between adjacent phenylenes are in the $60-70^{\circ}$ range, still sufficiently close to planarity to provide weak conjugation. Although tetraphenylenes were studied as inclusion compound hosts [98], relatively few were prepared in nonracemic form (Figure 15.22) [99-103]. The absolute configuration for tetranaphthylene $(R)-(+)-56$ was established recently by vibrational CD spectroscopy [86].

Recent advances in the synthesis of nonracemic tetraphenylenes relied on homocoupling (or cross-coupling) of enantiopure axially chiral binaphthyls $[(R)-56$ and 57] [101], asymmetric synthesis $[(R)-\mathbf{5 8}, \mathbf{- 5 9}$, and -60] [102] and racemic synthesis followed by resolution $[(R)-,(\mathrm{S})-\mathbf{6 1}, \mathbf{- 6 2}, \mathbf{- 6 3}$, and -64] [103].

Asymmetric synthesis of tetraphenylenes 58-60 consists of two key steps, as illustrated by the synthesis of tetraphenylene 58: (1) regioselective arylation at the ste-

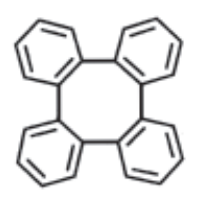

Tetraphenylene

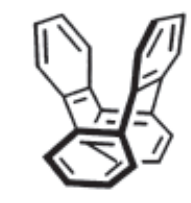

Tub-shape structure of tetraphenylene

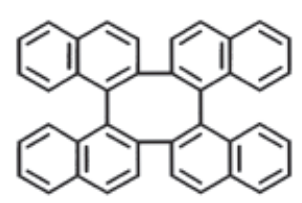

(R)-56

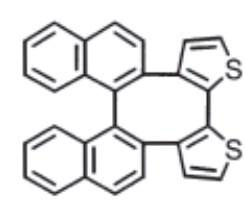

$(R)-57$

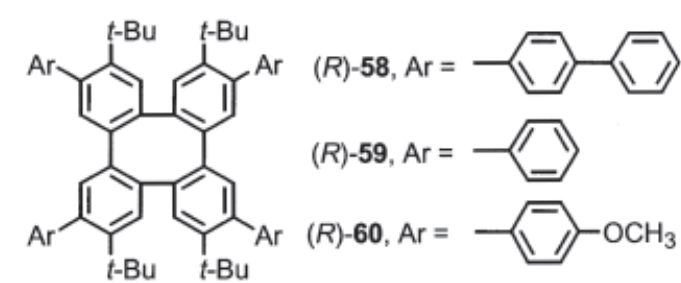

(R)-, (S)-61, $\mathrm{X}=\mathrm{H}, \mathrm{Y}=\mathrm{OH}$ (R)-, (S)-62, $\mathrm{X}=\mathrm{H}, \mathrm{Y}=\mathrm{PPh}_{2}$ $(R)-,(S)-63, \mathrm{X}=\mathrm{Y}=\mathrm{OH}$ $(R)-,(S)-64, \mathrm{X}==\mathrm{PPh}_{2}$

Figure $15.22 \mathrm{D}_{2 \mathrm{~d}}$-symmetric tetraphenylene and its chiral (nonracemic) derivatives. 


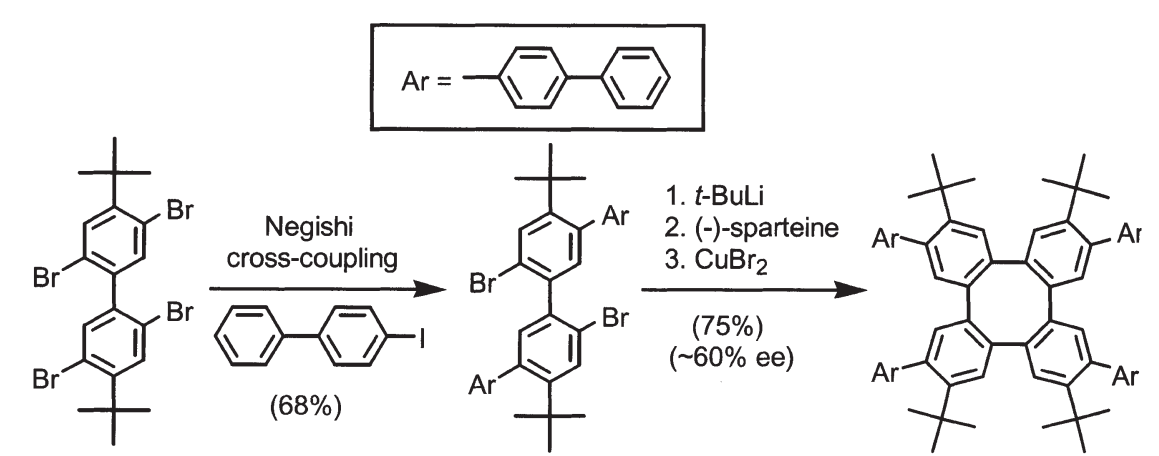

65

$(R)-58$
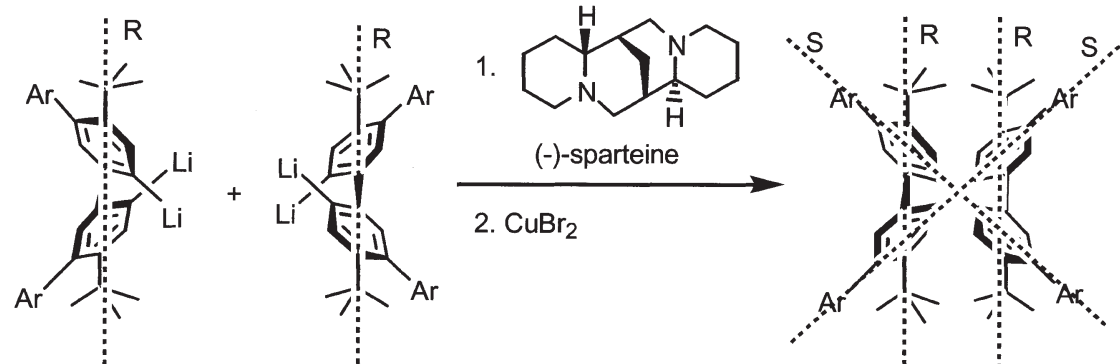

Figure 15.23 Asymmetric synthesis of tetraphenylenes. Chiral axes for the predominant enantiomer are indicated.

rically hindered biaryl positions, to give $\mathbf{6 5}$, and (2) annelation based on oxidative homocoupling of 2,2'-dilithiobiaryls in the presence of (-)-sparteine, to give nonracemic tetraphenylene $(R)-(+)-\mathbf{5 8}$ with $\sim 60 \%$ ee (Figure 15.23) [102]. Recrystallization provided enantiomerically pure $(R)-(+)-\mathbf{5 8}$. The absolute configuration of $(R)-(+)-58$ was established by CD spectroscopy [102].

Tetraphenylene may be viewed as a building block of "three-dimensional graphite," i.e. complete annelation of tetraphenylenes would give a three-dimensional carbon network $(P n 3 m)$. Such a relatively low strain structure (e.g. compared with fullerenes) was first considered by Riley and coworkers, in their studies of amorphous carbon. However, this structure remains experimentally elusive [104-106].

The achiral network of tetraphenylenes served as an inspiration for the design of a $\pi$-conjugated double helix. Double helical polymers, in which two polyphenylene helices are intertwined or tetraphenylenes are sequentially annelated, were recognized as the chiral building block of the network (Figure 15.24) [107].

Racemic synthesis of double helical octaphenylene 67 was carried out via a convergent route. In the annelation step, the $\mathrm{Cu}$ (II)-mediated oxidative homocoupling of dilithiotetraphenylene, derived from the dibromotetraphenylene 66, gave octaphenylene 67 (Figure 15.25) [107].

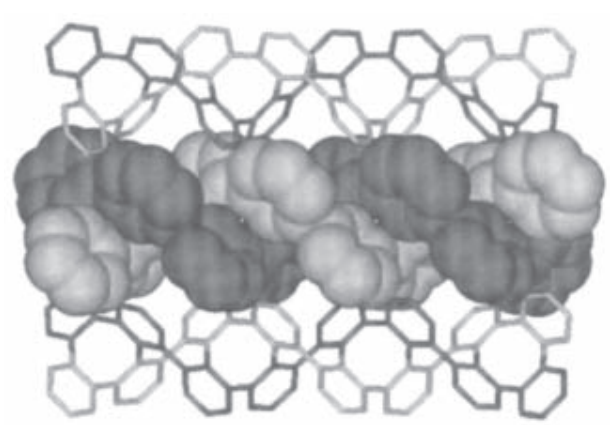

Figure 15.24 Double helical polyphenylenes as building blocks of "three-dimensional graphite".

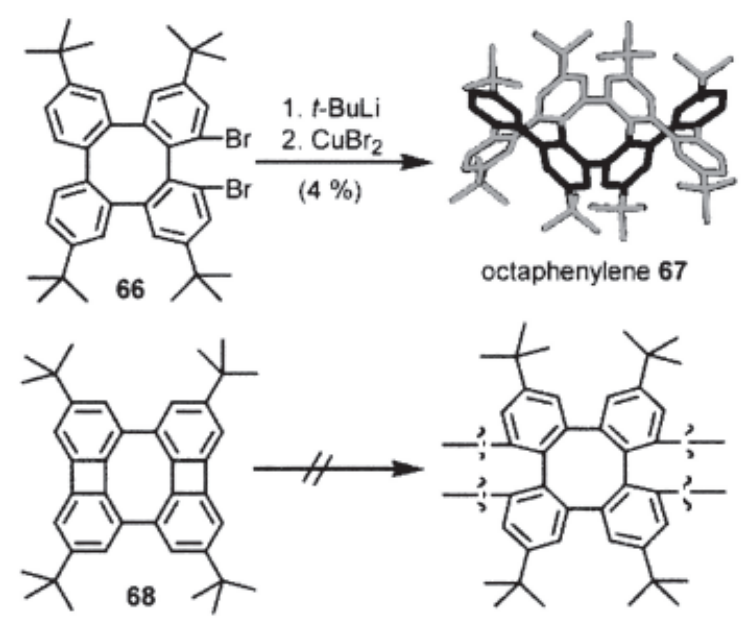

Figure 15.25 Synthesis of double helical octaphenylene 67.

Because starting material $\mathbf{6 6}$ was racemic and only homochiral tetraphenylenes may form a double helix, the yield of double helical product $\mathbf{6 7}$ was low and a significant amount (4\%) of a single CC-homocoupling product (presumably the meso diastereomer) was isolated. Analogous results were obtained in the synthesis of other tetraphenylenes; this includes observation of duplication-like effects with nonlinear increase in enantiomeric excess and tetraphenylene yield, when the starting biaryls had higher enantiomeric excess in the synthesis of tetranaphthalene $\mathbf{5 6}[101,108]$.

Biphenylene dimer $\mathbf{6 8}$, a building block for another putative carbon allotrope, was prepared [109]. However, the reaction of $\mathbf{6 8}$ under the conditions typical for the conversion of biphenylene to tetraphenylene failed to yield the double helical polymer or corresponding oligomer (Figure 15.25) [107].

Another racemic tetraarylene-based double helical fragment (71) was prepared by Marsella et al. using a divergent synthetic route [110]. The annelation step relied on $\mathrm{Pd} / \mathrm{Cu}$-mediated arylalkyne cross-coupling of tetrathienylene 69 and the dialkyne 70, providing 71 in good yield (Figure 15.26). 


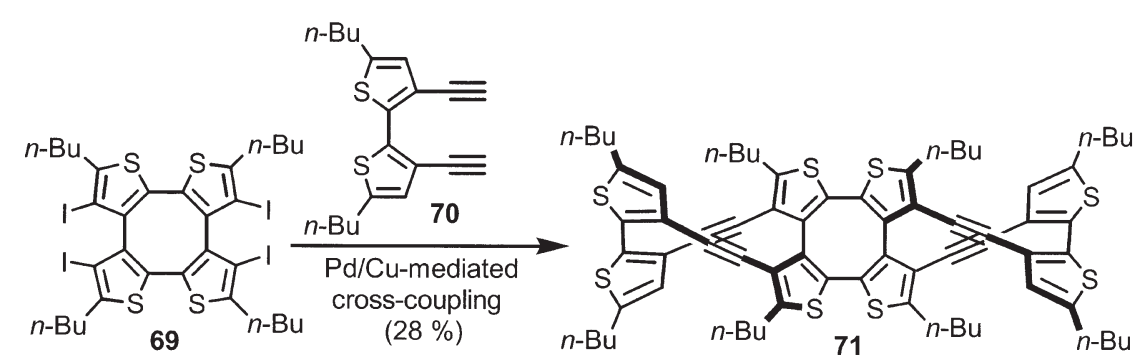

Figure 15.26 Synthesis of double helical octathienylene 71 .
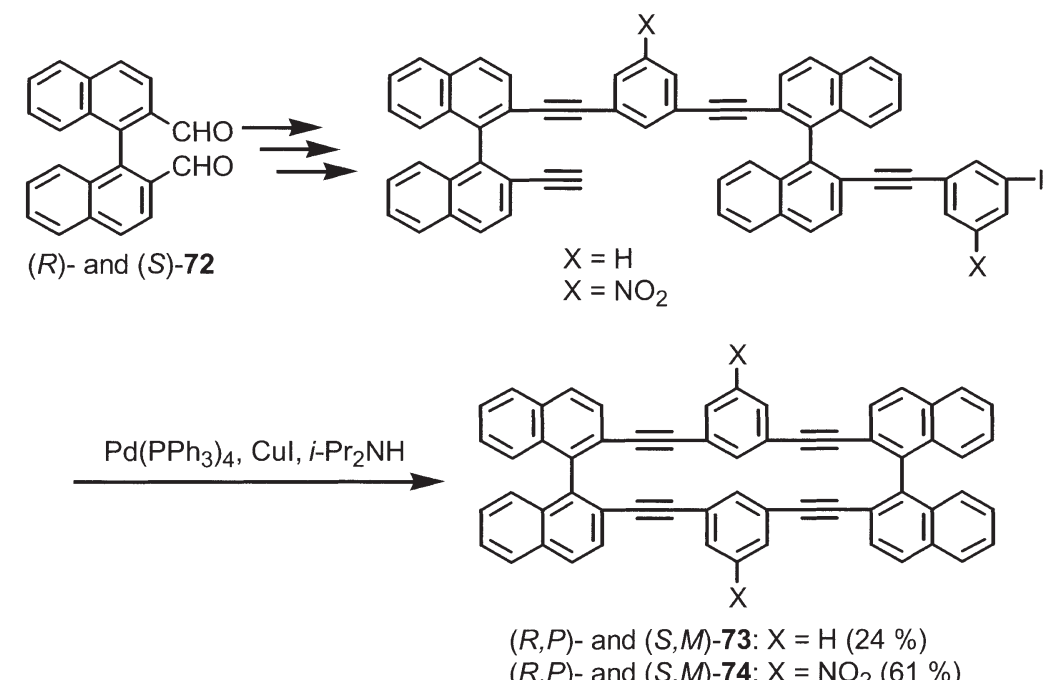

Figure 15.27 Synthesis of double helical m-conjugated molecules starting from enantiopure binaphthyls.

Analogous $\mathrm{Pd} / \mathrm{Cu}$-mediated arylalkyne annelation was employed to prepare binaphthyl-based double helical fragments in good yields [111]. Starting from enantiopure dialdehyde $\mathbf{7 2}$, both enantiomers of $\mathbf{7 3}$ and $\mathbf{7 4}$ could be obtained (Figure 15.27). The structure of racemic $\mathbf{7 4}$ was confirmed by X-ray crystallography.

Recently, Wong and coworkers reported a series of rod-like $D_{2}$-symmetric, enantiopure molecules, based on $\mathrm{Pt}(\mathrm{II})$ complexes of homochiral tetraphenylenes $(R)-63$, $(R)$-64 and $(R)$-BINAP. The highest homolog of such "chiral rod" had an estimated length of $4.8 \mathrm{~nm}$ [112].

Very few attempts at the reduction or oxidation of tetraarylenes have been made. For enantiopure tetranaphthalene $(R)-(+)-\mathbf{5 6}$, cyclic voltammetry showed one reversible wave at $-2.31 \mathrm{~V}$ (vs. SCE) corresponding to the reduction to the corresponding carbodianion $(R)-\mathbf{5 6}^{2-}$ (Figure 15.28) [101]. This wave was at significantly less negative potential than $-2.57 \mathrm{~V}$ for naphthalene under identical conditions. These results,

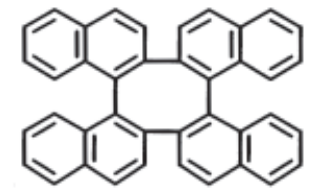

$(R)-56$

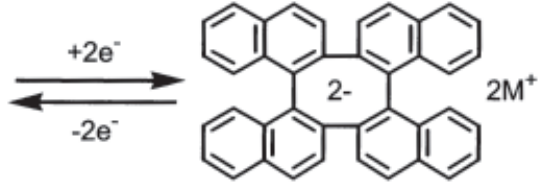

$(R)-56^{2-}, 2 \mathrm{M}^{+}(\mathrm{M}=\mathrm{Li}, \mathrm{Na})$

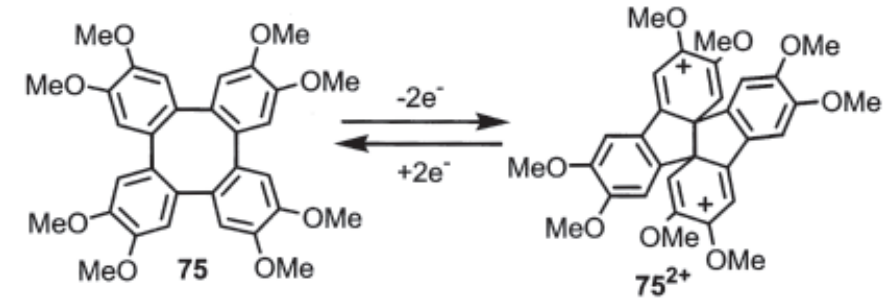

Figure 15.28 Reversible reduction and oxidation of tetraphenylenes to the corresponding diions.

and also the failure of the exciton coupling model in reproducing the $\mathrm{CD}$ spectra of $(R)-(+)-56$, were consistent with weak, but still significant, conjugation between naphthalene moieties. Notably, dihedral angles of $-70^{\circ}$ were found between naphthalene moieties in the X-ray structure of enantiopure $(R)-(+)-56$. Carbodianion $(R)-\mathbf{5 6}^{2-}$ $.2 \mathrm{M}^{+}(\mathrm{M}=\mathrm{Li}, \mathrm{Na})$ was prepared via reduction of $(R)-(+)-56$ with alkali metals gave carbodianion $(R)-\mathbf{5 6}^{2-} .2 \mathrm{M}^{+}(\mathrm{M}=\mathrm{Li}, \mathrm{Na})$; no intermediate radical anion could be detected or isolated, in agreement with the cyclic voltammetric data [101].

Oxidation of $\mathbf{5 6}$ to dication gives irreversible cyclic voltammetry, which was qualitatively similar to that found by Kochi and coworkers for the achiral tetraarylene $\mathbf{7 5}$ [113]. The cyclic voltammetric data were consistent with the reversible CC bond formation. Dication $\mathbf{7 5}^{2+} .2 \mathrm{SbCl}_{6}^{-}$was isolated and its hexacyclic structure was unequivocally determined by X-ray crystallography (Figure 15.28) [113].

\section{3}

\section{Barriers for Racemization ofChiral $\pi$-Conjugated Systems}

Configurational stability (or persistence) is one of the important properties of a chiral material. The definition of the lower limit for the free energy barrier for racemization may depend on the specific application. For optoelectronic applications, accelerated aging tests may provide very approximate guidelines [114]. For the purpose of estimating the free energy barrier for racemization, we will assume that the less than $1 \%$ conversion of the major enantiomer to the minor enantiomer in such aging tests is tolerable, i.e. $|\Delta \alpha \mathrm{t}| /|\alpha|<0.02$, where $\alpha$ (in units ${ }^{\circ} \mathrm{mm}^{-1}$ ) denotes rotatory power of thinfilm material. With these assumptions, the lower limit for the free energy barrier for racemization is of the order of $35 \mathrm{kcal} \mathrm{mol}^{-1}$. 
For $[n]$ helicenes, the free energy barriers for racemization increase with $n$ and with substitution at the inner helix sites [21, 115-117]. Thus, the free energy barriers (kcal $\mathrm{mol}^{-1}$ at $\left.27^{\circ} \mathrm{C}\right)$ for parent $[n]$ helicenes increase in the following order: $24.1(n=5)$, $36.2(n=6), 41.7(n=7), 42.4(n=8), 43.5(n=9)[115,117]$. [ $n]$ Thiahelicenes and $[n]$ helicenes with similar helical turns in-plane possess comparable barriers for racemization $[118,119]$. For methyl-substituted [6]helicenes, the barriers $\left(\mathrm{kcal} \mathrm{mol}^{-1}\right)$ are 43.8 (1-methyl), 44.0 (1,16-dimethyl), 39.5 (2,15-dimethyl). Similarly for 1methyl[5] helicene, the barrier increases to $38.7 \mathrm{kcal} \mathrm{mol}^{-1}$. Upon introduction of a sterically large substituent at the end of the inner helix, even [4]helicenes become configurationally stable at room temperature, e.g. [4]helicene $\mathbf{1 9}$ [70, 73, 120, 121]. Thus, modest steric hindrance at the ends of inner helices has a significant impact on the barrier for racemization, greater than that of extending the helix length well beyond a $360^{\circ}$ turn angle.

Carbon sulfur [7]helicene (M)-(-)-40, which has a relatively low turning angle but possesses two bulky bromine groups at the ends of the inner helix, has a free energy barrier for racemization of $39.0 \mathrm{kcal} \mathrm{mol}^{-1}$ (half-life of $11 \mathrm{~h}$ at $199{ }^{\circ} \mathrm{C}$ ) [85]. The relatively small helical turn in-plane (based on the X-ray structures of two racemic polymorphs) is apparently offset by two bulky bromine groups at the ends of the inner helix.

Notably, introduction of $\mathrm{sp}^{3}$-hybridized atoms into the helicene skeleton can significantly affect the barrier, e.g. the free energy barrier for racemization of 9,10dihydro[5] helicene is $29.9 \mathrm{kcal} \mathrm{mol}^{-1}$ [117].

Compared with $[n]$ helicenes, $[n]$ heliphenes possess significantly lower barriers for racemization - to the extent that the higher homologs, with the helix turn inplane exceeding $360^{\circ}$, are not resolvable at room temperature. Based on ${ }^{1} \mathrm{H}$ NMR spectroscopic decoalescence temperatures of the potentially diastereotopic methylene hydrogens of the methoxymethyl substituent in [7]-, [8]-, and [9]heliphene, free energy barriers for the inversion of configuration are $\Delta \mathrm{G}^{\ddagger}{ }_{-27^{\circ} \mathrm{C}}=12.6,13.4$, and $<$ $12 \mathrm{kcal} \mathrm{mol}^{-1}$, respectively [59,60]. These values were much lower than those for the corresponding $[n]$ helicenes. In addition, tetramethylated [7]heliphenes $6 \mathbf{d}$ and 6e did not even show any detectable diastereotopicity for the methylene hydrogens of the methoxymethyl substituent at temperatures as low as $-70{ }^{\circ} \mathrm{C}$. In contrast to $[n]$ helicenes, the barriers for racemization for $[n]$ heliphenes appeared to decrease with increase in steric hindrance of the methyl substitution on the terminal rings or with the increase in ring-ring overlap. It is plausible that the greater diameter of the helix turn and/or relatively low HOMO-LUMO gaps (and $E_{\mathrm{g}}$ ) in $[n]$ heliphenes might contribute to the greater conformational flexibility and then to the low barriers for racemization.

Conjoined double helicene 51-D, was obtained only as a racemate. Its barrier for racemization is expected to be significantly greater than the barrier of $24.1 \mathrm{kcal} \mathrm{mol}^{-1}$ for [5] helicene. The free energy barrier of $\sim 35 \mathrm{kcal} \mathrm{mol}^{-1}$ (half life of $\sim 3 \mathrm{~h}$ at $180{ }^{\circ} \mathrm{C}$

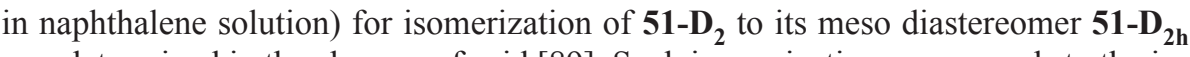
was determined in the absence of acid [89]. Such isomerization corresponds to the in-
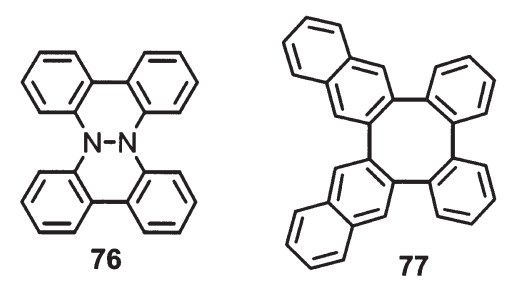

Figure 15.29 Structures of hydrazine 76 and tetraphenylene 77 .

version of one [5] helicene unit, compared with the inversion of both units that is required for racemization of 51-D $\mathbf{D}_{\mathbf{2}}$. The relatively high free energy barrier for inversion of one of the [5] helicene units may be associated with cooperativity in conformation conversion of the pentacyclic units, corresponding to diamine 50, from two chairs in the $D_{2}$ to two boats in the $C_{2 \mathrm{~h}}$ point group [89]. Also, double nitrogen inversion in the hydrazine moiety may contribute to the barrier [122]. Notably, double nitrogen inversion in both hydrazine moieties would be needed for racemization of 51-D 2 .

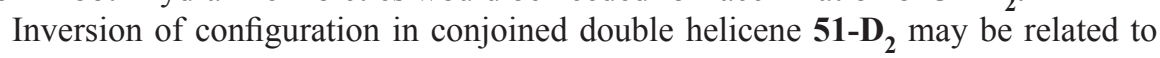
the barrier for racemization in a chiral hydrazine derivative, benzo[c] benzo[3,4]cinnolino[1,2-a]cinnoline (76) (Figure 15.29) [123-125]. In hydrazine 76, which is a diaza analog of dibenzo[ $g, p]$ chrysene, two [4] helicene fragments may be identified. Hydrazine 76 was characterized by X-ray crystallography and was readily resolvable via crystallization as a conglomerate [124]. Hydrazine $\mathbf{7 6}$ in decane racemized with an activation energy of $27.1 \mathrm{kcal} \mathrm{mol}^{-1}$, a process that may correspond to double nitrogen inversion [124]. Notably, oxidation of enantiomers of $\mathbf{7 6}$ resulted in optically inactive radical cations $[124,126]$. This is consistent with the contribution from double nitrogen inversion to the barrier for racemization in neutral $\mathbf{7 6 .}$

Barriers for inversion of configuration in chiral, overcrowded PAHs are relatively low. In hexabenzotriphenylene, a free energy barrier of $26.2 \mathrm{kcal} \mathrm{mol}^{-1}$ was found for isomerization of $\mathbf{5 3 -} \boldsymbol{C}_{\mathbf{2}}$ to the more thermodynamically stable $\mathbf{5 3}-\boldsymbol{D}_{\mathbf{3}}$. However, the free energy barrier for racemization in $\mathbf{5 3 -} C_{2}$, as determined from the ${ }^{1} \mathrm{H}$ NMR coalescence temperature $\left(\Delta G_{\mathrm{rac}}^{\ddagger}=11.7 \mathrm{kcal} \mathrm{mol}^{-1}, T_{\mathrm{c}}=247 \mathrm{~K}, \Delta v=102 \mathrm{~Hz}\right.$ at 500 $\mathrm{MHz}$ ), was relatively low [95]. Pentacene 55 (Figure 15.21), with a screw-type endto-end twist of $144^{\circ}$, racemized slowly at room temperature $\left(\Delta G^{\ddagger}{ }_{\text {rac }, 25^{\circ} \mathrm{C}}=23.8 \mathrm{kcal}\right.$ $\left.\mathrm{mol}^{-1}\right)$ [97], that is, the barrier for racemization is similar to that in [5] helicene $\left(\Delta G^{\ddagger}\right.$ rac $=24.1 \mathrm{kcal} \mathrm{mol}^{-1}$ ).

Among chiral $\pi$-conjugated systems, tetraphenylenes possess extraordinarily high barriers for racemization. This is in contrast to the relatively low barriers for PAHs, especially those based on triphenylene. Racemization of chiral tetraphenylene corresponds to ring inversion of the central cyclooctatetraene ring. The steric repulsion of the "bay hydrogen atoms" in typical tetraphenylenes is one of the reasons for the extraordinarily high barriers for racemization. For example, tetraphenylene 77 (Figure 15.29) has a free energy barrier for racemization of $67 \mathrm{kcal} \mathrm{mol}^{-1}$, compared with $\sim 10 \mathrm{kcal} \mathrm{mol}^{-1}$ for cyclooctatetraene $[100,127]$. Because the dian- 
ion of cyclooctatetraene itself is a planar, aromatic compound, the inversion barrier is expected to be lowered to an extent dependent upon the degree of aromatic character in the central eight-membered ring upon n-doping. This proposition was tested in tetranaphthylene $\mathbf{5 6}$ and its corresponding carbodianions $\mathbf{5 6}^{\mathbf{2}}, 2 \mathrm{M}^{+}(\mathrm{M}=$ $\mathrm{Li}^{+}, \mathrm{K}^{+}$) (Figure 15.24). The lower limit of the barrier for the ring inversion of the neutral $(R)-(+)-56$ is $\Delta G_{613 \mathrm{~K}}^{\ddagger}>54 \mathrm{kcal} \mathrm{mol}^{-1}$. This may be compared with $\Delta G^{\ddagger}{ }_{363 \mathrm{~K}}$ $=29 \mathrm{kcal} \mathrm{mol}^{-1}$ for analogous process in the carbodianion $(R)-\mathbf{5 6}^{\mathbf{2}}, 2 \mathrm{Na}^{+}$. Hence the free energy barrier for the ring inversion in the carbodianion is lowered by at least $25 \mathrm{kcal} \mathrm{mol}^{-1}$ and probably by more than $40 \mathrm{kcal} \mathrm{mol}^{-1}$, compared with the neutral compound [101].

\section{4}

\section{Strong Chiroptical Properties in Absorption, Emission and Refraction}

\subsection{1}

\section{Absorption and Emission}

The strength of chiroptical properties in both absorption and emission may be measured by the corresponding anisotropy factors ( $g$-values). The factor measuring the degree of circular polarization in absorption is defined as $g_{\text {abs }}=\Delta \varepsilon / \varepsilon=\left(\varepsilon_{\mathrm{L}}-\varepsilon_{\mathrm{R}}\right) / 0.5\left(\varepsilon_{\mathrm{L}}\right.$ $+\varepsilon_{R}$ ), where $\Delta \varepsilon$ is the difference in molar absorptivity of left- and right-handed circularly polarized light and $\varepsilon$ is defined as average absorptivity. The maximum value of $\left|g_{\text {abs }}\right|=2$ would be obtained when only either left- or right-circularly polarized light is absorbed. The intrinsic, molecular values of $\left|g_{\text {abs }}\right|$ are determined by the ratio of the of the magnetic transition moment $(m)$ to the electric transition moment $(\mu)$ and the relative orientation (with cosine dependence) of these two moments. For molecules in which transitions are electric dipole and magnetic dipole allowed, $\left|g_{\text {abs }}\right|=$ $|\Delta \varepsilon| / \varepsilon$ is of the order of $5 \times 10^{-3}$. For ( + )-[6]helicene 1 , the vectors $\boldsymbol{m}$ and $\mu$ are parallel and $g_{\text {abs }}=\Delta \varepsilon / \varepsilon=+7 \times 10^{-3}$ (at $325 \mathrm{~nm}$ ) may be estimated from the reported data $[21,128]$. CD spectra of $[n]$ helicenes may be calculated by time-dependent density functional theory (TD DFT) to provide the transition moments and the assignments of absolute configurations [129]. In cross-conjugated carbon-sulfur [7] helicene 40, which possesses similar helical geometry but with a relatively smaller helix turn, $g_{\text {abs }}$ $=\Delta \varepsilon / \varepsilon=-4 \times 10^{-3}\left(\right.$ at $285 \mathrm{~nm}, \Delta \varepsilon_{\max }=-117$ and $\left.\varepsilon=3.1 \times 10^{4} \mathrm{~L} \mathrm{~mol}^{-1} \mathrm{~cm}^{-1}\right)$ is estimated based on chiroptical data for the (-)-enantiomer.

Analogous $g$-values may be defined for the degree of circular polarization in emission [or circularly polarized photoluminescence $(\mathrm{CPPL})]$ and circularly polarized electroluminescence (CPEL), e.g. $g_{\mathrm{CPPL}}=2\left(I_{\mathrm{L}}-I_{\mathrm{R}}\right) /\left(I_{\mathrm{L}}+I_{\mathrm{R}}\right)$ where $I_{\mathrm{L}}$ and $I_{\mathrm{R}}$ denote the intensity of left- and right-handed circularly polarized emission, respectively. CPPL should not be confused with fluorescence-detected CD.

Materials with the highest values of $\left|g_{\text {abs }}\right|,\left|g_{\text {CPPL }}\right|$, and $\left|g_{\text {CPEL }}\right|$ are chirally aggregated molecules or polymers. In many cases, helical supramolecular structures (heli- cally twisted bundles, etc.) or liquid crystalline phases were detected by microscopy techniques. Consequently, such materials may have non-negligible contributions from linear polarization (e.g. cross-terms between linear birefringence and linear dichroism), polarization-dependent scattering and the usual cholesteric LC effects (e.g. selective reflection). Hence very strong polarization properties of such LC-like materials most likely originate at the supramolecular level, analogously to the conventional low molecular weight LC materials.

Bunz and coworkers reported random poly( $p$-phenylenethynylene) copolymers; maximum $g$-values were observed for the extensively annealed films of 1:1 copolymer [7]. Such films possessed $\left|g_{\text {abs }}\right|=0.38$ and $\left|g_{\text {CPPL }}\right|=0.19$ at $\lambda=432$ and 443 $\mathrm{nm}$, with linear dichroism $<<0.01$. Both wavelengths corresponded to maxima in the absorption and the emission. Both CD and CPPL spectra were monosignate in the regions of their maximum $g$-values, which was consistent with the absence of significant exciton coupling. Notably, the $g$-values were lower by a factor of more than 100 for the polymer with chiral-only pendants [7].

Among other polymers with large $g$-values, poly(fluorenes) with chiral pendants [e.g. 2(S)-methylbutyl, 2(R)-ethylhexyl] were perhaps most intensively studied [8, $130-133]$. For poly(fluorenes) with $2(R)$-ethylhexyl pendants, $\left|g_{\text {CPPL }}\right|=0.28$ and $\left|g_{\text {CPEL }}\right|=0.25$ were reported [131]. Similarly, large values of $\left|g_{\text {abs }}\right|$ were reported for other poly(fluorenes). The values of $\left|g_{\text {CPEL }}\right|$ may be compared with $\left|g_{\text {CPEL }}\right|=0.0013$ for the first circularly polarized LED based on chirally substituted PPV [134].

Chiroptical studies of poly(fluorenes) with 3(S),7-dimethyloctyl pendants revealed a strong dependence of $\left|g_{\text {abs }}\right|$ on the thickness of the annealed films. The sign inversion of $g_{\text {abs }}$ at a thickness of $30 \mathrm{~nm}$ and the maximum of $\left|g_{\text {abs }}\right| \approx 1$ at a thickness exceeding $200 \mathrm{~nm}$ were observed. Hence the very large values of $\left|g_{\text {abs }}\right|$ in thicker films might be associated with cross-terms between linear birefringence and linear dichroism, as opposed to the intrinsic CD of the polymer chains [132].

Careful studies by Chen and coworkers on well-defined oligo(fluorenes) identified a nonamer for which acholesteric structure was observed after annealing. An order of magnitude increase in $\mathrm{CD}$, disappearance of the signature of the exciton coupling and sign reversal in CPPL (and $g_{\mathrm{CPPL}}=+0.75$ for the $87-\mathrm{nm}$ thick film) were related to the right-handed cholesteric structure [133].

Very large values of $\left|g_{\text {CPPL }}\right|$ may be more easily obtained via doping of LCs, e.g. the near maximum value of $\left|g_{\text {CPPL }}\right|=1.8$ for $0.2 \%$ achiral ter(fluorene) doped in chiral nematic LC film (35- $\mu \mathrm{m}$ thick) at the wavelength range of selective reflection for the LC [135].

Katz's columnar aggregates of helicenes have relatively modest $g$-values, e.g. for $1 \mathrm{mM}$ solutions ofenantiopure derivative of [7]thiahelicene 11, $\left|g_{\mathrm{abs}}\right| \approx\left|g_{\mathrm{CPPL}}\right|=$ 0.01 [65]. For enantiopure [4]helicene 19 and [5]helicene 20, which were apparently non-aggregated, small values of $\left|g_{\text {abs }}\right| \approx\left|g_{\text {CPPL }}\right|=0.0008-0.001$ were reported [73]. 
15.4.2

\section{Refraction}

The degree of circular polarization in refraction is measured by the circular birefringence, $\left|n_{\mathrm{L}}-n_{\mathrm{R}}\right|$, where $n_{\mathrm{L}}$ and $n_{\mathrm{R}}$ correspond to the refractive indices for left-and right-handed polarized light, respectively. Thin films, with very large $\left|n_{\mathrm{L}}-n_{\mathrm{R}}\right|>10^{-4}$, which significantly exceeds linear birefringence $\left(\left|n_{0}-n_{\mathrm{e}}\right|\right)$ in the highly transparent region, may provide new means for the control of light polarization in planar optical waveguides ("chiral waveguides") $[6,136]$. Such materials should have excellent configurational stability, good processability and fast response.

For a typical chiral organic compound, such as 2-butanol, the circular birefringence, $\left|n_{\mathrm{L}}-n_{\mathrm{R}}\right|$, at $\lambda=589 \mathrm{~nm}$ is of the order of $10^{-7}$. Even for a very high $|\alpha|=40^{\circ}$ $\mathrm{mm}^{-1}$ at $\lambda=589 \mathrm{~nm}\left(\left|n_{\mathrm{L}}-n_{\mathrm{R}}\right| \approx 2 \times 10^{-4}\right)$, linear birefringence, which may arise from residual ordering/aggregation of polymer chains, could easily overwhelm the circular birefringence.

Very low values of linear birefringence are generally difficult to attain in thin films of macromolecules. Although it is possible to decrease the linear birefringence by doping the polymer film with inorganic crystals with opposite sign of linear birefringence, this procedure leads to significantly lower transparency and, possibly, introduces problems with optical homogeneity [137]. Vitrification by rapid cooling is possible for many low molecular weight compounds; however, such a method is difficult to apply to macromolecules and it would be impractical for the fabrication of thin films of optical quality [138].

Organic materials with large optical rotations include cholesteric liquid crystals, molecules and polymers with chiral $\pi$-conjugated systems, especially $[n]$ helicenes $[21,31,139]$. The most important factor contributing to their large optical rotations is anomalous optical rotatory dispersion (ORD), which is associated with the presence of absorption (or reflection) with large rotational strength (Figure 15.30).

Rigorously, ORD and CD spectra are related through the Kronig-Kramers theorem, a well-known general relationship between refraction and absorption, i.e. $n_{\mathrm{L}}-$ $n_{\mathrm{R}}$ is determined by $\varepsilon_{\mathrm{L}}-\varepsilon_{\mathrm{R}}$ for $\lambda$ from zero to infinity [128]. (The analogous relationship between refraction and reflection applies to cholesteric liquid crystals.) Hence, in order to maximize ORD in the transparent region, Cotton effects, associated with exciton coupling (both intramolecular and intermolecular), have to be avoided. This

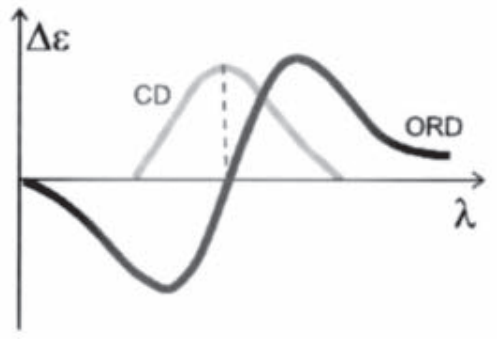

Figure 15.30 Anomalous optical rotatory dispersion (ORD) and circular dichroism (CD) spectra for the positive Cotton effect of a single, isolated electronic transition. implies that the chromophores have to be conjugated and molecules (or macromolecules) randomly oriented.

Among non-aggregated molecules and polymers, annelated $\pi$-conjugated molecules such as $[n]$ helicenes possess relatively large optical rotations [21]. Notably, specific rotations of helicenes and thiahelicenes increase significantly with the helix length; for (-)-[6]-, -[7]-, -[8]-, -[9]-, -[11]-, and-[13]helicenes in chloroform, $[\alpha]_{589}=$ $-3640,[\alpha]_{579}=-5900,[\alpha]_{579}=-7170,[\alpha]_{579}=-8150,[\alpha]_{579}=-9310$, and $[\alpha]_{579}=-$ $9620\left( \pm 100,10^{-1} \mathrm{deg} \mathrm{cm}^{2} \mathrm{~g}^{-1}\right)$ were reported, respectively [26, 49]. Anomalous ORD contributes in two ways to these increases in $[\alpha]$ for longer helices: (1) the wavelength for the measurement of $[\alpha](589$ and $579 \mathrm{~nm})$ is becoming closer to the absorption tail-off (e.g. 370 and $450 \mathrm{~nm}$ for [6]- and [9]-helicene, respectively) and (2) the longest wavelength Cotton effect in CD spectra is red -shifted and becomes more intense (e.g. $\Delta \varepsilon \approx 200 \mathrm{~L} \mathrm{~mol}^{-1} \mathrm{~cm}^{-1}$ at $\sim 330 \mathrm{~nm}$ and $270 \mathrm{~L} \mathrm{~mol}^{-1} \mathrm{~cm}^{-1}$ at $\sim 390 \mathrm{~nm}$ for [6]- and [9]-helicene, respectively). The $\mathrm{CD}$ bandwidth increases with increase in length of the helicene further contribute to the rotational strengths for longer helicenes. In this context, cross-conjugated carbon-sulfur $[n]$ helicenes, which become electron localized at $n \leq 7$, may provide both an excellent system for studies of intrinsic chiroptical properties (free of absorption tail-off effects) and chiroptical materials with a wide transparency range.

Substituent effects on the chiroptical properties of helicenes are relatively large but the corresponding structure-property relationships are not understood [50, 79, 85]

Enantiopure [7]thiahelicene $\mathbf{3 3}$ forms isotropic glassy films, with $\left|n_{0}-n_{\mathrm{e}}\right| \approx$ 0.0003 in the range $\lambda=630-1550 \mathrm{~nm}$. Similar results were obtained for enantiopure tetranaphthalene 56. The isotropicity of the thin films may be associated with the tetrahedral-like shapes (Figure 15.31), which are known to inhibit efficient crystal packing for achiral molecules. The rotatory power $|\alpha|=11$ and $6^{\circ} \mathrm{mm}^{-1}$ at 670 and 850 $\mathrm{nm}$, respectively, for [7]thiahelicene $\mathbf{3 3}$ are the highest attained to date for an isotropic material $[79,136,140]$.

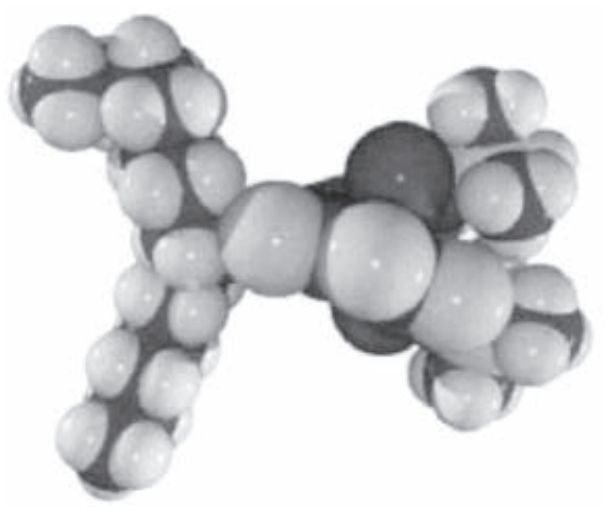

Figure 15.31 Space-filling plot for [7]thiahelicene 33 obtained from the X-ray structure of the racemic crystal. 


\section{5}

\section{Conclusion}

Although significant advances in the synthesis of well-defined oligomers with highly annelated chiral $\pi$-systems have been made, the synthesis of macromolecules with inherently strong chiral properties remains a challenge. This challenge is further amplified by the need to control configurational stability and achiral properties of the material.

To date, the stepwise, kinetically controlled, classical synthesis is the most effective approach to highly annelated chiral $\pi$-systems. With significant improvements in asymmetric annelation methodologies, multi-step syntheses are likely to remain the main tool in the exploration of novel chiral structures. However, the development of novel synthetic methods will be essential for the preparation of polymers with extended helical-type, ladder-type connectivity of the $\pi$-systems. Important criteria are to minimize the density of defects in the ladder connectivity and to provide conjugation pathways circumventing at least some of the defects.

\section{Acknowledgments}

We thank our collaborators who have contributed to this work and especially Dr. Suchada Rajca (University of Nebraska-Lincoln), Dr. Maren Pink (Indiana University) and Dr. Warren N. Herman (University of Maryland). Financial support was provided by the National Science Foundation (CHE-0414936), the Office of Naval Research (N00014-03-1-0550) and the Air Force Office of Scientific Research (FA9550-04-1-0056).

\section{References}

1. V. Percec, M. Glodde, T. K. Bera, Y. Miura, I. Shiyanovskaya, K. D. Singer, V. S. K. Balagurusamy, P. A. Heiney, I. Schnell, A. Rapp, H.-W. Spiess, S. D. Hudson, H. Duan, Self-organization of Supramolecular Helical Dendrimers into Complex Electronic Materials, Nature 2002, 419, 384-387.

2. S. Zahn, T. M. Swager, Three-dimensional Electronic Delocalization in Chiral Conjugated Polymers, Angew. Chem. Int. Ed. 2002, 41, 4225-4230.

3. (a) Ph. Leclere, M. Surin, P. Viville, R. Lazzaroni, A. F. M. Kilbinger, O. Henze, W. J. Feast, M. Cavallini, F. Biscarini, A. P. H. J. Schenning, E. W. Meijer, About Oligothiophene Self-assembly: From Aggregation in Solution to Solid-state Nanostructures, Chem. Mater. 2004, 16, 4452-4466; (b) C. R. L. P N. Jeukens, P. Jonkheijm, F. J. P. Wijnen, J. C. Gielen, P. C. M. Christianen, A. P. H. J. Schenning, E. W. Meijer, J. C. Maan, Polarized Emission of Individual Self-assembled Oligo ( $p$-phenylenevinylene)based Nanofibers on a Solid Support, J. Am. Chem. Soc. 2005, 127, 8280-8281.

4. (a) C. Li, M. Numata, A.-H. Bae, K. Sakurai, S. Shinkai, Self-assembly of Supramolecular Chiral Insulated Molecular Wire, J. Am. Chem. Soc. 2005, 127, 4548-4549; (b) J. Bae, J.-H. Choi, Y.-S. Yoo, N.K. Oh, B.-S. Kim, M. Lee, Helical Nanofibers from Aqueous Self-assembly of an Oligo( $p$-phenylene)based Molecular Dumbbell, J. Am. Chem. Soc. 2005, 127, 9668-9669.

5. A. Satrijo, T. M. Swager, Facile Control of Chiral Packing in Poly(p-phenylenevinylene) Spin-cast Films, Macromolecules, 2005, 38, 4054-4057.
6. W. N. Herman, Polarization Eccentricity of the Transverse Field for Modes in Chiral Core Planar Waveguides, J. Opt. Soc. Am. A 2001, 18, 2806-2818.

7. J. N. Wilson, W. Steffen, T. G. McKenzie, G. Lieser, M. Oda, D. Neher, U. H. F. Bunz, Chiroptical Properties of Poly( $p$-phenyleneethynylene) Copolymers in Thin Films: Large $g$-Values, J. Am. Chem. Soc 2002, 124, 6830-6831.

8. M. Oda, H.-G. Nothofer, G. Lieser, U. Scherf, S. C. J. Meskers, D. Neher, Circularly Polarized Electroluminescence from Liquid-crystalline Chiral Polyfluorenes, Adv. Mater. 2000, 12, 362-365.

9. Y. Miyamoto, S. G. Louie, M. L. Cohen, Chiral Conductivities of Nanotubes, Phys. Rev. Lett. 1996, 76 2121-2124.

10. G. L. J. A. Rikken, J. Foiling, P. Wyder, Electrical Magnetochiral Anisotropy, Phys. Rev. Lett. 2001, 87, 236602-1-236602-4.

11. V. Krsti, S. Roth, M. Burghard, K. Kern, G. L. J. A. Rikken, Magneto-chiral Anisotropy in Charge Transport through Single-walled Carbon Nanotubes, J. Chem. Phys. 2002, 117, 11315-11319.

12. L. Brunsveld, B. J. B. Folmer, E. W. Meijer, R. P. Sijbesma, Supramolecular Polymers, Chem. Rev 2001, 101, 4071-4098.

13. E. Yashima, K. Maeda, T. Nishimura, Detection and Amplification of Chirality by Helical Polymers, Chem. Eur. J. 2004, 10, 42-51.

14. H. Goto, K. Akagi, Optically Active Conjugated Polymers Prepared from Achiral Monomers by Polycondensation in a Chiral Nematic Solvent, Angew. Chem. Int. Ed. 2005, 44, 4322-4328.

15. L. Pu, 1,1'-Binaphthyl Dimers, Oligomers and Polymers: Molecular Recognition, Asymmetric Catalysis and New Materials, Chem. Rev. 1998, 98, 2405-2494.

16. D. J. Hill, M. J. Mio, R. B. Prince, T. S. Hughes, J. S. Moore, A Field Guide to Foldamers, Chem. Rev. 2001, 101, 3893-4012.

17. H. Sugiura, Y. Nigorikawa, Y. Saiki, K. Nakamura, M. Yamaguchi, Marked Effect of Aromatic Solvent on Unfolding Rate of Helical Ethynylhelicene Oligomer, J. Am. Chem. Soc. 2004, 126, 14858-14864.

18. Y. Dai, T. J. Katz, Synthesis of Helical Conjugated Ladder Polymers, J. Org. Chem. 1997, 62, 1274-1285.

19. T. Iwasaki, Y. Kohinata, H. Nishide, Poly(thiaheterohelicene): a Stiff Conjugated Helical Polymer Comprised of Fused Benzothiophene Rings, Org. Lett. 2005, 7, 755-758.

20. While functionalized chiral nanotubes and chiral fullerenes may provide molecularly well-defined materials in the future, their specialized chemistry is not covered in this overview.

21. P. P. Meurer, F. Vögtle, Helical Molecules in Organic Chemistry, Top. Curr. Chem. 1985, 127, 1-76.

22. W Fuchs, F. Niszel, Uber die Tautomerie der Phenole, IX.: Die Naphtho-carbazol-Bildung aus Naphtholen, Ber. Dtsch. Chem. Ges. 1927, 60, 209-212.

23. I. Pischel, S. Grimme, S. Kotila, M. Nieger, F. Vögtle, A Configurationally Stable Pyrrolohelicene: Experimental and Theoretical Structure-Chiriooptic Relationships, Tetrahedron: Asymmetry 1996, 7 , $109-116$.

24. J. W. Cook, Polycyclic Aromatic Hydrocarbons. Part XII. The Orientation of Derivatives of 1:2-Benzanthracene, with Notes on the Preparation of Some New Homologues and on the Isolation of 3:4:5:6Dibenzphenanthrene, J. Chem. Soc. 1933, 1952-1957.

25. M. S. Newman, D. Lednicer, The Synthesis and Resolution of Hexahelicene, J. Am. Chem. Soc. 1956, 78, 4765-4770.

26. R. H. Martin, The Helicenes, Angew. Chem. Int. Ed. Engl. 1974, 13, 649-659.

27. R. H. Martin, M. Bayes, Helicenes. Photosyntheses of [11], [12] and [14]Helicene, Tetrahedron 1975 31, 2135-2137.

28. [11]Thiahelicene: H. Wynberg, M. B. Groen, Reaction of Optically Active Heterohelicenes. Synthesis of an Optically Active Undecaheterohelicene, J. Am. Chem. Soc. 1970, 92, 6664-6665. 
29. H. Wynberg, Some Observations on the Chemical, Photochemical and Spectral Properties of Thiophenes Acc. Chem. Res. 1971, 4, 65-73.

30. K. Yamada, S. Ogashiwa, H. Tanaka, H. Nakagawa, H. Kawazura, [7], [9], [11], [13] and [15]Heterohelicenes Annelated with Alternant Thiophene and Benzene Rings. Syntheses and NMR Studies, Chem. Lett. 1981, 343-346.

31. T. J. Katz, Syntheses of Functionalized and Aggregating Helical Conjugated Molecules, Angew. Chem Int. Ed. 2000, 39, 1921-1923.

32. L. Liu, T. J. Katz, Simple Preparation of a Helical Quinone, Tetrahedron Lett. 1990, 31, 3983-3986.

33. R. Chang, S. I. Weisman, Electron Transfer between Anion and Molecule of Hexahelicene, J. Am Chem. Soc. 1967, 89, 5968.

34. S. Bamberger, D. Hellwinkel, F. A. Neugebauer, Uber verbruckte Diaryl- und Triarylamin-Radicalkationen, Chem. Ber. 1975, 108, 2416-2421.

35. K.-H. Ernst, M. Neuber, M. Grunze, U. Ellerbeck, NEXAFS Study on the Orientation of Chiral $(P)$ Heptahelicene on $\mathrm{Ni}(100)$, J. Am. Chem. Soc. 2001, 123, 493-495.

36. R. Fasel, M. Parschau, K.-H. Ernst, Chirality Transfer from Single Molecules into Self-assembled Monolayers, Angew. Chem. Int. Ed. 2003, 42, 5178-5181.

37. L. Vyklicky, S. H. Eichhorn, T. L. Katz, Helical Discotic Liquid Crystals, Chem. Mater: 2003, 15, 3594-3601.

38. T. W. Bell, N. M. Hext, Supramolecular Optical Chemosensors for Organic Analytes, Chem. Soc. Rev. 2004, 33, 589-598.

39. D. J. Weix, S. D. Dreher, T. J. Katz, [5]HELOL Phosphite: a Helically Grooved Sensor of Remote Chirality, J. Am. Chem. Soc. 2000, 122, 10027-10032.

40. M. T. Reetz, S. Sostmann, 2,15-Dihydroxy-hexahelicene (HELIXOL): Synthesis and Use as an Enantioselective Fluorescent Sensor, Tetrahedron 2001, 57, 2515-2520.

41. I. Sato, R. Yamashima, K. Kadowaki, J. Yamamoto, T. Shibata, K. Soai, Asymmetric Induction by Helical Hydrocarbons: [6]- and [5]Helicenes, Angew. Chem. Int. Ed. 2001, 40, 1096-1098.

42. Y. Xu, Y. X. Zhang, H. Sugiyama, T. Umano, H. Osuga, K. Tanaka, $(P)$-Helicene Displays Chiral Selection in Binding to Z-DNA, J. Am. Chem. Soc. 2004, 126, 6566-6567.

43. S. Honzawa, H. Okubo, S. Anzai, M. Yamaguchi, K. Tsumoto, I. Kumagai, Chiral Recognition in the Binding of Helicenediamine to Double Strand DNA: Interactions between Low Molecular Weight Helical Compounds and a Helical Polymer, Bioorg. Med. Chem. 2002, 10. 3213-3218.

44. F. B. Mallory, C. S. Wood, J. T. Gordon, Photochemistry of Stilbenes. III. Some Aspects of the Mechanism of Photocyclization to Phenanthrenes, J. Am. Chem. Soc. 1964, 86, 3094-3102.

45. M. Flammang-Barbieux, J. Nasielski, R. H. Martin, Synthesis of Heptahelicene (1) Benzo[c]phenanthro[4,3-g]phenanthrene, Tetrahedron Lett. 1967, 743-744.

46. Conglomerates of [7]-, [8]- and [9]helicene: R. H. Martin, M.-J. Marchant, Resolution and Optical Properties $\left([\alpha]_{\max }\right.$, ord and cd) of Hepta-, Octa- and Nonahelicene, Tetrahedron 1974, 30, 343-345.

47. Although racemic [6]helicene $\mathbf{1}$ also may also be crystallized as a conglomerate, the effective resolution is prevented by lamellar twinning, i.e. formation of alternate layers (10-30 $\mu \mathrm{m}$ thick) of molecules with opposite configuration: B. S. Green, M. Knossow, Lamellar Twinning Explains the Nearly Racemic Composition of Chiral, Single Crystals of Hexahelicene, Science 1981, 214, 795-797.

48. H. Nakagawa, S. Ogashiwa, H. Tanaka, K. Yamada, H. Kawazura, Optical Resolution of Heterohelicenes by High Performance Liquid Chromatography, Bull. Chem. Soc. Jpn. 1981, 1903-1904.

49. R. H. Martin, V. Libert, Helicenes. The Use of Resolved Hexahelicene-2-carboxylic Acid as a Common Precursor for the Photochemical Synthesis of Optically Pure Octa-, Deca-, Undeca- and Tridecahelicenes. Thermal Racemization of Deca- and Undeca-helices, J. Chem. Res. (S) 1980, 130-131.
50. C. Wachsmann, E. Weber, M. Czugler, W. Seichter, New Functional Hexahelicenes - Synthesis, Chiroptical Properties, X-ray Crystal Structures and Comparative Data Bank Analysis of Hexa-helicenes, Eur. J. Org. Chem. 2003, 2863-2876.

51. J. Larsen, K. Bechgaard, Thiaheterohelicenes 1. Synthesis of Unsubstituted Thia[5]-, [9]- and [13]heterohelicenes Acta Chem. Scand. 1996, 50, 71-76.

52. E. Murguly, R. McDonald, N. R. Banda, Chiral Discrimination in Hydrogen-bonded [7]Helicenes, $\mathrm{Org}$. Lett. 2000, 2, 3169-3172.

53. T. Caronna, R. Sinisia, M. Catellani, S. Luzzati, L. Malpezzia, S. V. Meillea, A. Melea, C. Richter, R. Sinisi, Molecular Crystal Architecture and Optical Properties of a Thiohelicenes Series Containing 5, 7, 9 and 11 Rings Prepared via Photochemical Synthesis, Chem. Mater. 2001, 13, 3906-3914.

54. S. Maioranam, A. Papagni, E. Licandro, R. Annunziata, P. Paravidino, D. Perdicchia, C. Giannini, M. Bencini, K. Clays, A. Persoons, A Convenient Procedure for the Synthesis of Tetrathia-[7]-helicene and the Selective $\alpha$-Functionalisation of Terminal Thiophene Ring, Terahedron Lett. 2003, 59, 6481-6488.

55. R. E. Abed, B. B. Hassine, J.-P. Genet, M. Gorsane, A. Marinetti, An Alternative Procedure for the Synthesis of [5]- and [7]Carbohelicenes, Eur. J. Org. Chem. 2004, 1517-1522.

56. K. Sato, S. Okazaki, T. Yamaguchi, S. Aral, The Synthesis of Azoniadithia[6]-helicene, J. Heterocyl. Chem. 2004, 41, 443-447.

57. C. Bazzini, S. Brovelli, T. Caronna, C. Gambarotti, M. Giannone, P. Macchi, F. Meinardi, A. Mele, W. Panzeri, F. Recupero, A. Sironi, R. Tubino, Synthesis and Characterization of Some Aza[5]-helicenes, Eur. J. Org. Chem. 2005, 1247-1257.

58. C. Baldoli, A. Bossi, C. Giannini, E. Licandro, S. Maiorana, D. Perdicchia, M. Schiavo, A Novel and Efficient Approach to (Z)-1,2-Bis(benzodithienyl)ethene Precursors of Tetrathia[7]helicenes, Synlett 2005, 1137-1141.

59. S. Han, A. D. Bond, R. L Disch, D. Holmes, J. M. Schulman, S. J. Teat, K. P. C. Vollhardt, G. D. Whitener, Total Syntheses and Structures of Angular [6]- and [7]Phenylene: the First Helical Phenylenes (Heliphenes), Angew. Chem. Int. Ed. 2002, 41, 3223-3227.

60. S. Han, D. R. Anderson, A. D. Bond, H. V. Chu, R. L. Disch, D. Holmes, J. M. Schulman, S. J. Teat, K. P. C. Vollhardt, G. D. Whitener, Total Syntheses and Structures of Angular [7]-, [8]- and [9]Phenylene by Triple Cobalt-catalyzed Cycloisomerization: Remarkably Flexible Heliphenes, Angew. Chem. Int. Ed. 2002, 41, 3227-3230.

61. M. Klessinger, J. Michi, Excited States and Photochemistry of Organic Molecules, VCH, New York, 1995, pp. 440-442.

62. J. Larsen, K. Bechgaard, Direct Oxidative Cyclization of 1,2-Bis(benzothio-phene-2-yl)ethylenes as a Replacement of Photocyclization in the Synthesis of Thiaheterohelicenes, J. Org. Chem. 1996, 61, $1151-1152$.

63. J. M. Fox, T. J. Katz, Conversion of a [6]Helicene into an [8]Helicene and a Helical 1,10-Phenanthroline Ligand, J. Org. Chem. 1999, 64. 302-305.

64. M. Miyasaka, A. Rajca, M. Pink, S. Rajca, Cross-conjugated Oligothiophenes Derived from the $\left(\mathrm{C}_{2} \mathrm{~S}_{\mathrm{n}}\right.$ Helix: Asymmetric Synthesis and Structure of Carbon-Sulfur [11]Helicene, J. Am. Chem. Soc. 2005, 127, 13806-13807.

65. K. E. S. Phillips, T. J. Katz, S. Jockusch, A. J. Lovinger, N. J. Turro, Synthesis and Properties of an Aggregating Heterocyclic Helicene, J. Am. Chem. Soc. 2001, 123, 11899-11907.

66. C. Nuckolls, T. J. Katz, G. Katz, P. J. Collings, L. Castellanos, Synthesis and Aggregation of a Conjugated Helical Molecule, J. Am. Chem. Soc. 1999, 121, 79-88.

67. J. M. Fox, T. J. Katz, S. V. Elshocht, T. Verbiest, M. Kauranen, A. Persoons, T. Thongpanchang, T. Krauss, L. Brus, Synthesis, Self-assembly and Nonlinear Optical Properties of Conjugated Helical Metal Phthalocyanine Derivatives, J. Am. Chem. Soc. 1999, 121, 3453-3459. 
68. C. Nuckolls, T. J. Katz, T. Verbiest, S. V. Elshocht, H.-G. Kuball, S. Kiesewalter, A. J. Lovinger, A. Persoons, Circular Dichroism and UV-Visible Absorption Spectra of the Langmuir-Blodgett Films of an Aggregating Helicene, J. Am. Chem. Soc. 1998, 120, 8656-8660.

69. T. Verbiest, S. Van Elshocht, M. Kauranen, L. Hellemans, J. Snauwaert, C. Nuckolls, T. J. Katz, A. Persoons, Strong Enhancement of Nonlinear Optical Properties Through Supramolecular Chirality, Science 1998, 282, 913-915.

70. D. Hellwinkel, W. Schmidt, Zweifach orthoverbruckte Triphenylamin-Derivate, Chem. Ber. 1980, 113, 358-384.

71. Improved procedure: J. L. Fox, C. H. Chen, J. F. Stenberg, An Improved Synthesis of 5,5,9,9-Tetramethyl-5H,9H-quino[3,2,1-de]acridine Org. Prep. Proced. Int. 1985, 17, 169-173.

72. J. E. Field, T. J. Hill, D. Venkataraman, Bridged Triarylamines: a New Class of Heterohelicenes, $J$. Org. Chem. 2003, 68, 6071-6078.

73. J. E. Field, G. Muller, J. P. Riehl, D. Venkataraman, Circularly Polarized Luminescence from Bridged Triarylamine Helicenes, J. Am. Chem. Soc. 2003, 125, 11808-11809.

74. M. Gingras, F. Dubois, Synthesis of Carbohelicenes and Derivatives by Carbenoid Couplings, Tetrahedron Lett. 1999, 40. 1309-1312.

75. Y. Ogawa, M. Toyama, M. Karikomi, K. Seki, K. Haga, T. Uyehara, Synthesis of Chiral [5] Helicenes Using Aromatic Oxy-Cope Rearrangement as a Key Step, Terahedron Lett. 2003, 44, 2167-2170.

76. H. J. Bestmann, W. Both, Determination of the Absolute Configuration of (+)-Pentahelicene, Angew. Chem. Int. Ed. Engl. 1972, 11, 296.

77. I. G. Stara, I. Stary, M. Tichy, J. Zavada, V. Hanus, Stereochemical Dichotomy in the Stevens Rearrangement of Axially Twisted Dihydroazepinium and Dihydrothiepinium Salts. A Novel Enantio-selective Synthesis of Pentahelicene, J. Am. Chem. Soc. 1994, 116, 5084-5088.

78. K. Tanaka, H. Suzuki, H. Osuga, Non-photochemical Route to Chiral Disubstituted [7]Thiaheterohelicenes via Biaryl- and Carbonyl-coupling Reactions, J. Org. Chem. 1997, 62, 4465-4470.

79. M. Miyasaka, A. Rajca, M. Pink, S. Rajca, Chiral Molecular Glass: Synthesis and Characterization of Enantiomerically Pure Thiophene-based [7] Helicene, Chem. Eur. J. 2004, 10, 6531-6539.

80. M. C. Carreño, M González-López, A. Urbano, Efficient Asymmetric Synthesis of [7] Helicene Bisquinones, Chem. Commun. 2005, 611-613.

81. A. Urbano, Recent Developments in the Synthesis of Helicene-like Molecules, Angew. Chem. Int. Ed. 2003, 42, 3986-3989.

82. F. Teplý, I. G. Stará, I. Starý, A. Kollároviè, D. Šaman, L. Rulíšek, P. Fiedler, Synthesis of [5]-, [6]and [7]Helicene via $\mathrm{Ni}(\mathrm{O})$ - or $\mathrm{Co}(\mathrm{I})$-Catalyzed Isomerization of Aromatic cis,cis-Dienetriynes, J. Am. Chem. Soc. 2002, 124, 9175-9180

83. F. Teplý, I. G. Stará, I. Starý, A. Kollároviè, D. Šaman, S. Vyskoèil, P. Fiedler, Synthesis of 3-Hexahelicenol and Its Transformation to 3-Hexahelicenylamines, Diphenylphosphine, Methyl Carboxylate and Dimethylthiocarbamate, J. Org. Chem. 2003, 68, 5193-5197.

84. A. Rajca, H. Wang, M. Pink, S. Rajca, Annelated Heptathiophene: a Fragment of a Carbon-Sulfur Helix, Angew. Chem. Int. Ed. 2000, 39, 4481-4483.

85. A. Rajca, M. Miyasaka, M. Pink, H. Wang, S. Rajca, Helically Annelated and Cross-conjugated Oligothiophenes: Asymmetric Synthesis, Resolution and Characterization of a Carbon-Sulfur [7]Helicene, $J$. Am. Chem. Soc. 2004, 126, 15211-15222.

86. T. B. Friedman, X. Cao, A. Rajca, H. Wang, L. A. Nafie, Determination of Absolute Configuration in Two Molecules with Chiral Axes by Vibrational Circular Dichroism: A $C_{2}$-symmetric Annelated Heptathiophene and a $D_{2}$-symmetric Dimer of 1,1'-Binaphthyl, J. Phys. Chem. A 2003, 107, 7692-7696.

87. M. Miyasaka, A. Rajca, Synthesis of a Short Carbon-Sulfur Helicene: Pd-catalyzed Cross-coupling at the $\beta$-Positions of Thiophenes, Synlett 2004, 177-182.
88. D. Peña, A. Cobas, D. Pérez, E. Guitián, L. Castedo, Dibenzo[a,o]phenanthro[3,4-s]pycene, a Configurationally Stable Double Helicene: Synthesis and Determination of Its Conformation by NMR and GIAO Calculations, Org. Lett. 2003, 5, 1863-1866.

89. K. Shiraishi, A. Rajca, M. Pink, S. Rajca, $\pi$-Conjugated Conjoined Double Helicene via a Sequence of Three Oxidative CC- and NN-Homocouplings, J. Am. Chem. Soc. 2005, 127, 9312-9313.

90. Two NN homocouplings in cyclodehydrogenation of tetra(benziimidazol-2-yl)benzenes: W. Wu, A. C. Grimsdale, K. Mullen, Cyclodehydrogenation of Di- and Tetra(benzimidazol-2 -yl)benzenes to give Model Heteroaromatic Discotic Systems, Chem. Commun. 2003, 1044-1045.

91. A. Rajca, M. Pink, unpublished data.

92. J. Wu, Z. Tomovic, V. Enkelmann, K. Mullen, From Branched Hydrocarbon Propellers to $C_{3}$-Symmetric Graphite Disks J. Org. Chem. 2004, 69, 5179-5186.

93. L. Barnett, D. M. Ho, K. K. Baldridge, R. A. Pascal Jr., The Structure of Hexabenzotriphenylene and the Problem of Overcrowded $D_{3 \mathrm{~h}}$ Polycyclic Aromatic Compounds, J. Am. Chem. Soc. 1999, 121, 727-733.

94. A. A. Bennett, M. R. Kopp, E. Wenger, A. C. Willis, Generation of Nickel(0)-Aryne and Nickel(II)-Biphenyldiyl Complexes via in situ Dehydrohalogenation of Arenas. Molecular Structures of $\left[\mathrm{Ni}\left(2,2^{\prime}-\right.\right.$ $\left.\mathrm{C}_{6} \mathrm{H}_{4} \mathrm{C}_{6} \mathrm{H}_{4}\right) \mathrm{dcpe}$ )] and Q-Hexabenzotriphenylene, J. Organomet. Chem. 2003, 667, 8-15.

95. D. Peña, A. Cobas, D. Pérez, E. Guitián, L. Castedo, Kinetic Control in the Palladium-catalyzed Synthesis of $C_{2}$-Symmetric Hexabenzotriphenylene. A Conformational Study, Org. Lett. 2000, 2, 1629-1632.

96. B. Gomez-Lor, A. M. Echavarren, Synthesis of a Triaza Analogue of Crushed Fullerene by Intramolecular Palladium-catalyzed Arylation, Org. Lett. 2004, 6, 2993-2996.

97. J. Lu, D. M. Ho, N. J. Vogelaar, C. M. Krami, R. A. Pascal, Jr., A Pentacene with a $144^{\circ}$ Twist, $J . A m$ Chem. Soc. 2004, 126, 11168-11169.

98. T. C. W. Mak, H. N. C. Wong, Inclusion Properties of Tetraphenylene and Synthesis of Its Derivatives, Top. Curr. Chem. 1987, 140, 142-164.

99. Barrier for racemization of $45^{+} \mathrm{kcal} \mathrm{mol}^{-1}$ : D. Gust, G. H. Senkler, Jr., K. Mislow, Resolution and Optical Stability of Tetrabenzocyclo-octatetraene Derivatives, J. Chem. Soc., Chem. Commun. 1972, 1345.

100. P. Rashidi-Ranjbar, Y.-M. Man, J. Sandstrom, H. N. C. Wong, Enantiomer Resolution, Absolute Configuration and Attempted Thermal Racemization of Two Tetrabenzocyclooctatetraene ( $o$-Tetraphenylene) Derivatives. An Exceptionally High Barrier to Ring Inversion, J. Org. Chem. 1989, 54 4888-4892.

101. (a) A. Rajca, A. Safronov, S. Rajca, J. Wongsriratanakul, $D_{2}$-Symmetric Dimer of 1,1'-Binaphthyl and Its Chiral $\pi$-Conjugated Carbodianion, J. Am. Chem. Soc. 2000, 122, 3351-3357; (b) A. Rajca, J. Li, unpublished data.

102. A. Rajca, H. Wang, P. Bolshov, S. Rajca, Greek Cross Dodecaphenylene: Sparteine-mediated Asymmetric Synthesis of Chiral $D_{2}$-Symmetric $\pi$-Conjugated Tetra-o-phenylenes, Tetrahedron 2001, 57, $3725-3735$.

103. J.-F. Wen, W. Hong, K. Yuan, T. C. W. Mak, H. C. N. Wong, Synthesis, Resolution and Applications of 1,16-Dihydroxytetraphenylene as a Novel Building Block in Molecular Recognition and Assembly, J. Org. Chem. 2003, 68, 8918-8931.

104. J. Gibson, M. Holohan, H. L. Riley, Amorphous Carbon, J. Chem. Soc. 1946, 456-461.

105. H. L. Riley, Chemical and Crystallographic Factors in Carbon Combustion, J. Chim. Phys. Phys. Chim. Biol. 1950, 565-572.

106. F. Diederich, Y. Rubin, Synthetic Approaches Toward Molecular and Polymeric Carbon Allotropes, Angew. Chem. Int. Ed. Engl. 1992, 31, 1101-1123.

107. A. Rajca, A. Safronov, S. Rajca, R. Schoemaker, Double Helical Octaphenylene, Angew. Chem. Int Ed. Engl. 1997, 36, 488-491. 
108. Review including discussion of duplication method: H. B. Kagan, J. C. Fiaud, Kinetic Resolution, Top. Stereochem. 1988, 18, 249-330.

109. A. Rajca, A. Safronov, S. Rajca, C. R. Ross, II, J. J. Stezowski, Biphenylene Dimer. Molecular Fragment of a Two-dimensional Carbon Net and Double-stranded Polymer, J. Am. Chem. Soc. 1996, 118 7272-7279.

110. M. J. Marsella, I. T. Kim, F. Tham, Toward Conjugated Double Helical Ladder Polymers: Cyclooctatetrathiophene as a Highly Versatile Double Helical Scaffold, J. Am. Chem. Soc. 2000, 122, 974-975.

111. D. L. An, T. Nakano, A. Orita, J. Otera, Enantiopure Double-helical Alkynyl Cyclophanes, Angew. Chem. Int. Ed. 2002, 41, 171-173.

112. H.-Y. Peng, C.-K. Lam, T. C. W. Mak, Z. Cat, W-T. Ma, Y.-X. Li, H. N. C. Wong, Chiral Rodlike Platinum Complexes, Double Helical Chains and Potential Asymmetric Hydrogenation Ligand Based on Linear Building Blocks: 1,8,9,16-Tetrahydroxytetraphenylene and 1,8,9,16-Tetrakis(diphenylphosphin o)tetraphenylene, J. Am. Chem. Soc. 2005, 127, 9603-9611.

113. R. Rathore, P. LeMagueres, S. V Lindeman, J. K. Kochi, A Redox-controlled Molecular Switch Based on the Reversible C-C Bond Formation in Octamethoxytetraphenylene, Angew. Chem. Int. Ed. 2000, 39, 809-812

114. Accelerated aging tests for optoelectronic devices are typically carried out at 70 or $85^{\circ} \mathrm{C}$ for 2000 5000 h, e.g. based upon Telcordia (Bellcore) standards GR-468-CORE, Reliability Assurance Requirements for Optoelectronic Devices Used in Telecommunications Equipment.

115. R. H. Martin, M. J. Marchant, Thermal Racemisation of Hepta-, Octa- and Nonahelicene: Kinetic Results, Reaction Path and Experimental Proofs that the Racemisation of Hexa- and Heptahelicene Does Not Involve an Intramolecular Double Diels-Alder Reaction, Tetrahedron 1974, 30, 347-349.

116. R. H. Janke, G. Haufe, E.-U. Würthwein, J. H. Borkent, Racemization Barriers of Helicenes: a Computational Study, J. Am. Chem. Soc. 1996, 118. 6031-6035.

117. C. Goedicke, H. Stegemeyer, Resolution and Racemization of Pentahelicene, Tetrahedron Lett. 1970, 937-940.

118. K. Yamada, H. Nakagawa, H. Kawazura, Thermal Racemization of Thiaheterohelicenes. Bull. Chem. Soc. Jpn. 1986, 59, 2429-2432.

119. I. Navaza, G. Tsoucaris, G. Le Bas, A. Navaza, C. de Rango, General Models for Helicenes, Bull. Soc. Chim. Belg. 1979, 88, 863-870

120. C. Herse, D. Bas, F. C. Krebs, T Burgi, J. Weber, T. Wesolowski, B. W. Laursen, J. Lacour, A Highly Configurationally Stable [4]Heterohelicenium Cation, Angew. Chem. Int. Ed. 2003, 42, 3162-3166.

121. B. Laleu, P. Mobian, C. Herse, B. W. Laursen, G. Hopfgartner, G. Bernardinelli, J. Lacour, Resolution of [4]Heterohelicenium Dyes with Unprecedented Pummerer-like Chemistry, Angew. Chem. Int. Ed. 2005, 44, 1879-1883.

122. S. F. Nelsen, T. B. Frigo, Y. Kim, J. A. Thompson-Colon, Double Nitrogen Inversion in Sesquibicyclic Hydrazines and Their Cation Radicals, J. Am. Chem. Soc.1986, 108. 7926-7934.

123. Benzo $[c]$ benzo[3, 4$]$ cinnolino[ $[1,2-a]$ cinnoline: F. A. Neugebauer, S. Kuhnhäuser, A Triphenylamine Double-decker, Angew. Chem. Int. Ed. Engl. 1985, 24, 596-597.

124. H. Fischer, C. Krieger, F. A. Neugebauer, Benzo[c]benzo[3,4]cinnolino[1,2-o]cinnoline, a Chiral Hydrazine Derivative, Angew. Chem. Int. Ed. Engl. 1986, 25, 374-375.

125. M. Dietrich, J. Heinze, C. Krieger, F. A. Neugebauer, Electrochemical Oxidation and Structural Changes of 5,6-Dihydrobenzo[c]cinnolines, J. Am. Chem. Soc. 1996, 118. 5020-5030.

126. F. A. Neugebauer, M. Bock, S. Kuhnhäuser, H. Kurreck, Darstellung, ESR- und ENDOR-Untersuchung von Radicalkationen des Tetraphenylhydrazins, des 5,6-Dihydro-5,6-diphenylbenzo[c]-cinnolins und des Benzo[c]benzo[3,4]cinnolino[1,2-o]cinnolines, Chem. Ber. 1986, 119, 980-990.
127. Barrier of about $10 \mathrm{kcal} \mathrm{mol}^{-1}$ for the ring inversion in cyclooctatetraenes: L. A. Paquette, in $\mathrm{Ad}$ vances in Theoretically Interesting Molecules, Thummel, R. P. (Ed.), JAI Press, Greenwich, CT, 1992, Vol. 2, p. 1.

128. E. L. Eliel, S. H. Wilen, Stereochemistry of Organic Compounds, Wiley, New York, 1994, Chapter 13, pp. $991-1118$.

129. F. Furche, R. Ahlrichs, C. Wachsmann, E. Weber, A. Sobanski, F. Vögtle, S. Grimme, Circular Dichroism of Helicenes Investigated by Time-dependent Density Functional Theory, J. Am. Chem. Soc. 2000, 122, 1717-1724.

130. G. Lieser, M. Oda, T. Miteva, A. Meisel, H.-G. Nothofer, U. Scherf, D. Neher, Ordering, Graphoepitaxial Orientation and Conformation of a Polyfluorene Derivative of the Hairy-rod Type on an Oriented Substrate of Polyimide, Macromolecules 2000, 33, 4490-4495.

131. M. Oda, H.-G. Nothofer, U. Scherf, V. Sunjic, D. Richter, W. Regenstein, D. Neher, Chiroptical Properties of Chiral Substituted Polyfluorenes, Macromolecules 2002, 35, 6792-6798.

132. M. R. Craig, P. Jonkheijm, S. C. J. Meskers, A. P. H. J. Schenning, E. W. Meijer, The Chiroptical Properties of a Thermally Annealed Film of Chiral Substituted Polyfluorene Depend on Film Thickness, Adv. Mater. 2003, 15, 1435-1438.

133. Y. Geng, A. Trajkovska, D. Katsis, J. J. Ou, S. W. Culligan, S. H. Chen, Synthesis, Characterization and Optical Properties of Monodisperse Chiral Oligofluorenes, J. Am. Chem. Soc. 2002, 124, 8337-8347.

134. E. Peeters, M. P. T. Christiaans, R. A. J. Janssen, H. F. M. Schoo, H. P. J. M. Dekkers, E. W. Meijer, Circularly Polarized Electroluminescence from a Polymer Light-emitting Diode, J. Am. Chem. Soc.1997, 119, 9909-9910.

135. S. H. Chen, D. Katsis, A. W. Schmid, J. C. Mastrangelo, T. Tsutsui, T. N. Blanton Circularly Polarized Light Generated by Photoexcitation of Luminophores in Glassy Liquid-crystal Films, Nature 1999, 397, 506-508

136. Y. Kim, W. L. Cao, J. Goldhar, C. H. Lee, W. N. Herman, Optical Waveguides from Amorphous Chiral Binaphthyl Films, Polym. Prepr. 2002, 43, 594-595.

137. H. Ohkita, A. Tagaya, Y. Koike, Preparation of a Zero-birefringence Polymer Doped with a Birefringent Crystal and Analysis of Its Characteristics, Macromolecules 2004, 37, 8342-8348.

138. K. Saito, M. Massalska-Arodz, S. Ikeuchi, M. Maekawa, J. Sciesinski, E. Sciesinska, J. Mayer, T. Wasiutynski, M. Sorai, Thermodynamic Study on a Chiral Glass Former, 4-(1-Methylheptyloxy)-4'-cyanobiphenyl, J. Phys. Chem. B 2004, 108, 5785-5790.

139. McDonnell, D. G. Thermochromic Cholesteric Liquid Crystals, in Thermotropic Liquid Crystals, Gray, G. W. (Ed.), Wiley, Chichester, 1987, Chapter 5, pp. 120-144.

140. Y. Kim, W. N. Herman, unpublished data. 